\title{
Tide transformation in the Guadalquivir estuary (SW Spain) and process-based zonation
}

\author{
M. Díez-Minguito, ${ }^{1}$ A. Baquerizo, ${ }^{1}$ M. Ortega-Sánchez, ${ }^{1}$ G. Navarro, ${ }^{2}$ and M. A. Losada ${ }^{1}$ \\ Received 3 June 2011; revised 5 January 2012; accepted 13 January 2012; published 13 March 2012.
}

[1] This study analyzes tide transformation in the Guadalquivir estuary (SW Spain).

When fresh water discharges are less than $40 \mathrm{~m}^{3} / \mathrm{s}$, the estuary is tidally-dominated

(flood-dominated) and well mixed. Under such conditions, the estuary can be divided into three stretches, each characterized by a different tide propagation process. In the first stretch of $25 \mathrm{~km}$, the dominant process is diffusion. In the next stretch, approximately over $35 \mathrm{~km}$ length, convergence and friction processes are in balance. At the head of the estuary, in the last stretch, the tidal motion is partially standing because of tidal reflection on the Alcalá del Río dam, located $110 \mathrm{~km}$ upstream from the estuary mouth. The reflection coefficient $R$ varies with the frequency; for diurnal constituents its magnitude $\left|R_{D}\right|$ is 0.25 ; this value increases in the case of semi-diurnal $\left(\left|R_{S}\right| \approx 0.40\right)$, and quarter-diurnal constituents $\left(\left|R_{Q}\right| \approx 0.65\right)$, and reaches its minimum at the sixth-diurnal components $\left(\left|R_{X}\right| \approx 0.10\right)$. The tidal reflection can generate residual currents that have consequences in the bed morphology. Furthermore, when the fresh water discharges are greater than $400 \mathrm{~m}^{3} / \mathrm{s}$, the estuary is fluvially-dominated and the water level can be calculated as the linear superposition of tide and river contributions. However, superposition arguments do not hold for currents at any point in the estuary.

Citation: Díez-Minguito, M., A. Baquerizo, M. Ortega-Sánchez, G. Navarro, and M. A. Losada (2012), Tide transformation in the Guadalquivir estuary (SW Spain) and process-based zonation, J. Geophys. Res., 117, C03019, doi:10.1029/2011JC007344.

\section{Introduction}

[2] The Guadalquivir estuary is located in the southwest part of the Iberian Peninsula $\left(36^{\circ} 43^{\prime} \mathrm{N}-37^{\circ} 32^{\prime} \mathrm{N}, 5^{\circ} 56^{\prime} \mathrm{W}-\right.$ $\left.6^{\circ} 30^{\prime} \mathrm{W}\right)$ and its waters mix with those of the Gulf of Cádiz (Atlantic Ocean). The estuary extends $110 \mathrm{~km}$ inland from its mouth at Sanlúcar de Barrameda to the Alcalá del Río dam (Figure 1). The dam is the last monitoring point of the fresh water flow of the Guadalquivir River and the upstream tidal limit. The tidal range at the mouth is mesotidal $(3.5 \mathrm{~m}$ in spring tides) and the main tidal period is semidiurnal.

[3] The estuary is convergent (Figure 2) with cross-sections ranging from $4525 \mathrm{~m}^{2}$ in the Port of Bonanza to $580 \mathrm{~m}^{2}$ at the Alcalá del Río dam. Widths vary from $800 \mathrm{~m}$ near the mouth to $150 \mathrm{~m}$ at the head. They show a mild exponential decrease, with a convergence length of approximately $60 \mathrm{~km}$. The channel mean depth is $7.1 \mathrm{~m}$.

[4] Since the beginning of the 18th century and throughout the past century, the natural course of the estuary has been modified several times. It has been dammed, and the width and depth of the main channel have been enlarged. Currently, the estuary is being periodically dredged from its

\footnotetext{
${ }^{1}$ Grupo de Dinámica Flujos Ambientales, Centro Andaluz de Medio Ambiente, IISTA, Universidad de Granada, Granada, Spain.

${ }^{2}$ Department of Ecology and Coastal Management, Instituto de Ciencias Marinas de Andalucía, Consejo Superior de Investigaciones Científicas, Puerto Real, Spain.

Copyright 2012 by the American Geophysical Union. 0148-0227/12/2011JC007344
}

mouth to where it accesses the Port of Seville in order to guarantee a minimum navigation channel depth of $6.5 \mathrm{~m}$.

[5] The freshwater discharges from the Alcalá del Río dam are approximately $80 \%$ of the river water received by the estuary. These discharges are seasonal and reflect the effects of the regulation of the hydrographic basin upstream from the dam. Freshwater contributions to the estuary have decreased by an average of $60 \%$, from approximately $5000 \mathrm{hm}^{3} / \mathrm{yr}$ in $1931-1981$ to $2000 \mathrm{hm}^{3} / \mathrm{yr}$ in 1981-2000, with a greater reduction in dry-year cycles (data provided by the Spanish Ministry of the Environment).

[6] In the last 50 years, a substantial part of the forest and wetlands have disappeared and become farmlands and urban settlements. Approximately one-fourth of the total surface of the estuary is now part of the Doñana Nature Park, a freshwater wetland that is isolated from the estuarine tidal flow by walls and floodgates [Contreras and Polo, 2010]. The estuary is currently composed of a main channel with a few tidal creeks, but without any significant intertidal zones. This reduction of the tidal prism, along with other factors, has altered the mouth and the morphology of the adjacent coastline (A. López-Ruiz et al., Shoreline sand waves on curvilinear coasts, submitted to Geomorphology, 2011).

[7] At present, the estuary and its immediate surroundings are home to 1.7 million occupants clustered in 90 population settlements. Despite its socio-economic and environmental significance and its impact on shelf ecosystems, there is a surprising lack of scientific and technical information on the Guadalquivir estuary. Most research has studied its 


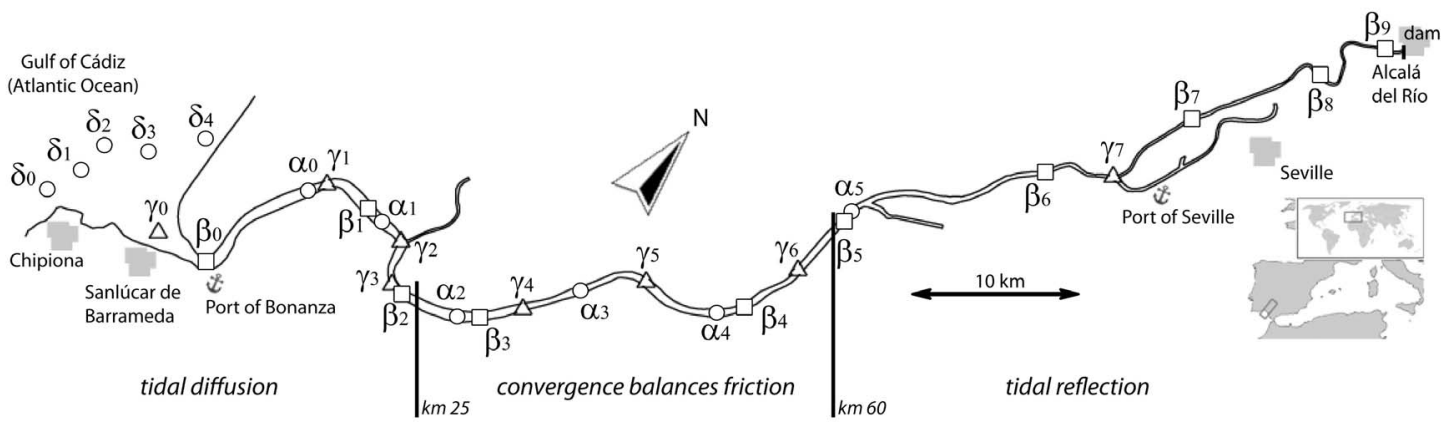

Figure 1. Map of study area, marking the location of the monitoring network stations. The monitoring network is composed of current-meter profilers, ADCPs (circles, $\alpha_{i}$ ), tidal gauges (squares, $\beta_{i}$ ) and environmental quality probes or CTDs (triangles, $\gamma_{i}$ ). The network also includes five current-meters placed in the perimeter of the mouth on the inner continental shelf (circles, $\delta_{i}$ ). The origin of the along-channel coordinate $(\mathrm{km} 0)$ was established at monitoring station $\gamma_{0}$, at the mouth. The Alcalá del Río dam, which is upstream tidal limit, is situated at $\mathrm{km} 110$ from $\gamma_{0}$. The river branch at Seville, which is separated from the main channel by a lock, is part of the installations at the Port of Seville. The three stretches are separates by the solid lines. The dominant processes which characterize them are also indicated.

hydrological description [Vanney, 1970], the impact of extreme natural events [González-Ortegón et al., 2010], and the effect of the Aznalcóllar mine spill [Grimalt et al., 1999] on the biota and primary production. In contrast, only a few research studies (mostly in Spanish) have focused on hydrodynamic aspects [Álvarez et al., 2001] and have analyzed the flow regimes, based on bed forms [Costa et al., 2009]. Oceanographic research on the shelf of the Gulf of Cádiz (Atlantic Ocean), into which the estuary flows, has focused on the general circulation of the Gulf [Garcia-Lafuente et al., 2006], its relation to Mediterranean water masses through the Strait of Gibraltar [Ambar and Howe, 1979], and to the pelagic ecosystem [Garcia-Lafuente and Ruiz, 2007]. The exchange of water masses between the Guadalquivir River and the continental shelf has not yet been characterized. The lack of knowledge regarding estuarine dynamics and the overexploitation of the estuary has generated and is still generating conflicts of interests. This makes decision-making processes extremely difficult.

[8] In 2008, the Regional Government funded the deployment of a real-time, remote monitoring network located all along the main course of the estuary and the inner continental shelf [Navarro et al., 2011], which is described in the following section, and which has provided simultaneous data of water velocities and level, among others, over the last three years.

[9] Based on those measurements, this study analyzes tidal propagation and transformation in the estuary within the context of different river flow regimes. This analysis follows previous studies carried out in other estuaries [Jay et al., 1990; Sherwood et al., 1990; Friedrichs and Aubrey, 1994; Friedrichs et al., 1998; Uncles, 2002; Savenije and Veling, 2005; Geyer and Chant, 2006; Hickey et al., 2010]. From a hydraulic perspective, the Guadalquivir estuary is similar to many of these estuaries. However, its main difference is the prominent wave reflection on the Alcalá del Río dam and its significant impact on the dynamics and morphology of at least one-third of the estuary.

[10] This article is organized as follows. Section 2 describes the monitoring network and characterizes the expected natural forcings of the estuary. Section 3 describes the harmonic analysis of elevations and currents during tidally-dominated and well-mixed conditions and when no dredging was performed. These data were used to evaluate the tidal asymmetry, the spring-neap variability, and the oscillatory motion type. Also discussed is the tidal diffusion in the first stretch near the mouth and the balance between convergence and dissipation in the central stretch of the estuary. Section 4 provides the linear analysis of the wave reflection at the dam and studies the possible bar formation associated with partial-standing

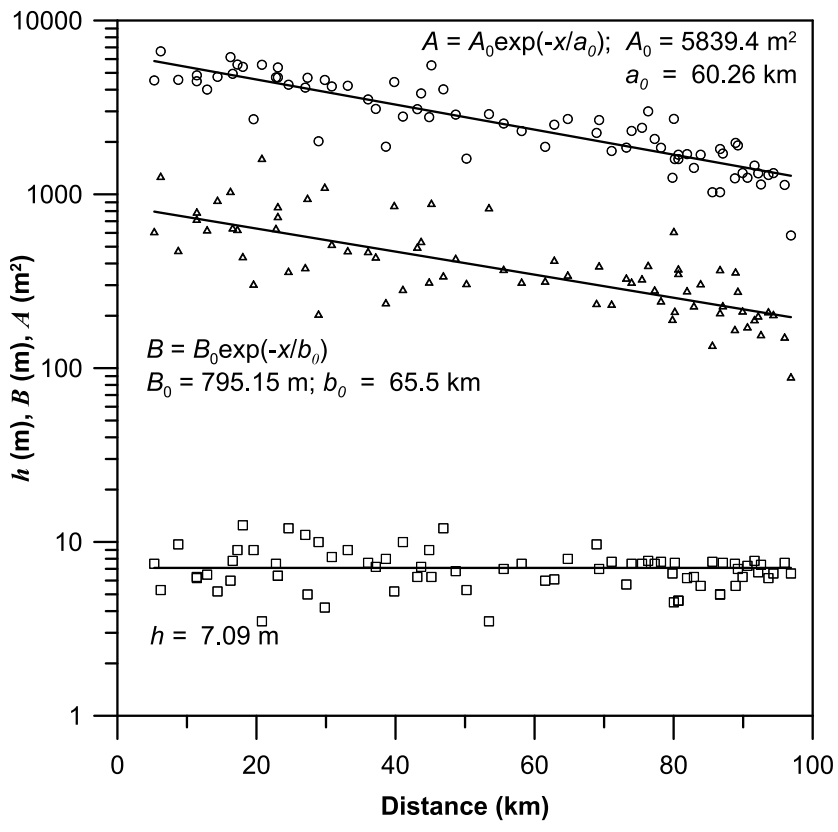

Figure 2. Tidally-averaged channel depth $h$ (squares), width $B$ (triangles), and cross-section $A$ (circles) throughout the estuary. Also shown are the exponential fit curves and parameters for $A$ and $B$ as well as the linear fit for $h$. Bathymetric measurements were carried out by the Port Authority of Seville. 
Table 1. Along-Channel Positions Where the Current-Meters $\alpha_{i}$ are Located ${ }^{\mathrm{a}}$

\begin{tabular}{cccccc}
\hline$\alpha_{0}$ & $\alpha_{1}$ & $\alpha_{2}$ & $\alpha_{3}$ & $\alpha_{4}$ & $\alpha_{5}$ \\
\hline 14.30 & 20.80 & 31.80 & 39.80 & 49.30 & 63.80 \\
\hline${ }^{\mathrm{a}}$ Units &
\end{tabular}

${ }^{\mathrm{a}}$ Units are in kilometers.

wave. Section 5 summarizes the tidal transformation in the Guadalquivir estuary during tidally-dominated conditions. Finally, section 6 presents and analyzes the results obtained during the river flood of 2009-2010, thus verifying the hypothesis of the linear superposition of water levels caused by the tide and river flows. The final section presents the conclusions that can be derived from this research.

\section{Monitoring Network and Natural Forcing Agents}

[11] In 2008, a real-time, remote monitoring network was deployed between the Alcalá del Río dam and the inner continental shelf (see Figure 1). Full details of the network and its equipment are given by Navarro et al. [2011, 2012]. The locations of the moorings in Figure 1 as well as their coordinates and kilometer points along the channel, starting from monitoring station $\gamma_{0}$, are specified in Tables 1-4.

[12] Six Acoustic Doppler Current Profilers (ADCPs), designated by $\alpha_{i}$, provided velocity data in the water column (Figure 1 and Table 1). The current-meters are moored pointing downwards in navigational buoys of the Port of Seville, measuring from the free water surface to the bottom. They provide one data set per meter and four profiles per hour with an integration period of $2 \mathrm{~min}$. They also record water temperature at $1 \mathrm{~m}$ from the free water surface. In this study current velocities are positive upstream.

[13] The water level was recorded with an array of ten tidal gauges, $\beta_{i}$, placed on the bed along the estuary channel (Figure 1 and Table 2). These gauges provide water surface and temperature every $10 \mathrm{~min}$. The tidal gauge $\beta_{0}$, property of Puertos del Estado and located in the Port of Bonanza, has been collecting data since 1992 .

[14] Eight environmental quality stations (CTD), denoted by $\gamma_{i}$, were also installed in the navigation buoys (Figure 1 and Table 3). These devices measured temperature, conductivity, dissolved oxygen, turbidity, chlorophyll, and fluorescence every $30 \mathrm{~min}$ at four depths $(z=-1,-2,-3$, and $-4 \mathrm{~m}$ with respect to the free water surface).

[15] The monitoring network included another set of current-meter profilers, $\delta_{i}$, moored on the bottom near the mouth (Figure 1). These instruments recorded variations of the free water surface (two of them had an Acoustic Surface Tracking module to record wave parameters), dynamic pressure, and current profile in the entire water column. The mean depth of the moorings is also shown in Table 4.

Table 2. Locations of the Tidal Gauges $\beta_{i}{ }^{\mathrm{a}}$

\begin{tabular}{cccccccccc}
\hline$\beta_{0}$ & $\beta_{1}$ & $\beta_{2}$ & $\beta_{3}$ & $\beta_{4}$ & $\beta_{5}$ & $\beta_{6}$ & $\beta_{7}$ & $\beta_{8}$ & $\beta_{9}$ \\
\hline 5.30 & 21.55 & 26.80 & 36.45 & 51.80 & 62.55 & 76.00 & 93.73 & 99.97 & 108.5 \\
\hline
\end{tabular}

${ }^{\mathrm{a}}$ Units are in kilometers.
Table 3. Locations Where the CTDs $\left(\gamma_{i}\right)$ Are Located, With Respect to the Estuary Mouth ${ }^{\mathrm{a}}$

\begin{tabular}{cccccccc}
\hline$\gamma_{0}$ & $\gamma_{1}$ & $\gamma_{2}$ & $\gamma_{3}$ & $\gamma_{4}$ & $\gamma_{5}$ & $\gamma_{6}$ & $\gamma_{7}$ \\
\hline 0 & 17.30 & 23.60 & 26.20 & 35.30 & 47.10 & 57.60 & 84.30 \\
\hline
\end{tabular}

${ }^{\mathrm{a}}$ Units are in kilometers.

[16] Daily data of discharges from the Alcalá del Río dam were obtained from the Regional Water Management Agency (Agencia Andaluza del Agua, Junta de Andalucía).

[17] With this data set, as well as others from different information sources, a database of simultaneous data was created, which is currently being used by government agencies to manage the Guadalquivir estuary [Bramato et al., 2009].

[18] With the data measured by the monitoring network and the available historical records, Table 5 summarizes the natural agents which can force or affect the dynamics of the Guadalquivir estuary, according to their probable range of occurrence and their concomitance. Normal, extreme, and exceptional conditions are defined. Table 5 also shows the threshold values and range of variation of the variables that characterize the different forcing agents in the Guadalquivir estuary, its nearshore and the continental shelf.

[19] Normal conditions refer to good weather conditions, local wind and wind waves, low freshwater discharge, and tidal dominance. They represent the basic state of the Guadalquivir estuary, which is slowly modulated by spring-neap cycles and local wind and wind waves.

[20] Extreme conditions can produce deep modifications of the basic state of the estuary, particularly in the morphology of the inlet. Tidal dynamics and their processes in the estuary are significantly affected by continental shelf dynamics and river discharges. The ratio between the meteorological and astronomical amplitudes varies within the range $[0.1,1]$, atmospheric pressure variations can be as large as $60 \mathrm{mbar}$, and the significant wave height and peak period can reach $10 \mathrm{~m}$ and $16 \mathrm{~s}$, respectively. River discharges, almost entirely regulated by dams, can easily exceed ten times the values of the basic state, i.e. $400 \mathrm{~m}^{3} / \mathrm{s}$. For completeness, the exceptional conditions (very rare events) and some information about tsunamis are also included. There are morphological evidences about the importance of historical tsunami events in the actual configuration of the estuary.

[21] In this research only the tidally-dominated (normal conditions) and the fluvially-dominated regimes are analyzed.

\section{Tidally-Dominated Regime (Good Weather Conditions)}

[22] The distribution of the daily river discharge released by the Alcalá del Río dam since 1980 (Figure 3) is bimodal

Table 4. Monitoring Devices Moored at the Estuary Mouth ${ }^{\mathrm{a}}$

\begin{tabular}{lccccc}
\hline & $\delta_{0}$ & $\delta_{1}$ & $\delta_{2}$ & $\delta_{3}$ & $\delta_{4}$ \\
\hline Distance $(\mathrm{km})$ & -10.9 & -9.1 & -11.6 & -11.1 & -16.2 \\
Latitude $^{\circ} \mathrm{N}$ & 36.7293 & 36.7597 & 36.8018 & 36.8378 & 36.9110 \\
Longitude $^{\circ} \mathrm{W}$ & 6.4951 & 6.4898 & 6.5160 & 6.4909 & 6.4681 \\
$h(\mathrm{~m})$ & 17.5 & 15.5 & 16 & 14 & 10 \\
\hline
\end{tabular}

${ }^{\mathrm{a}}$ The linear distance in kilometers is indicated with respect to the origin $\gamma_{0}$, latitude in ${ }^{\circ} \mathrm{N}$, longitude in ${ }^{\circ} \mathrm{W}$, and the mean water level. 
Table 5. Forcings and Regimes ${ }^{\mathrm{a}}$

\begin{tabular}{|c|c|c|c|c|c|c|}
\hline \multirow[b]{2}{*}{ Variables } & \multirow[b]{2}{*}{ Agent } & \multirow[b]{2}{*}{ Scale } & \multirow[b]{2}{*}{ Forcing } & \multicolumn{3}{|c|}{ Conditions } \\
\hline & & & & Normal $^{b}$ & Extreme & Exceptional \\
\hline Sea level, $\eta_{a}(m)$, Spring tides & Tide & Semidiurnal & Astronomical & $\eta_{a} \approx 3$ & - & - \\
\hline Sea level, $\eta_{a}(m)$, Neap tides & Tide & Semidiurnal & Astronomical & $\eta_{a} \approx 1$ & - & - \\
\hline Wind velocity, $u_{10}(\mathrm{~m} / \mathrm{s})$ & Surge & 1-7 days & Storm & - & $7.5 \leq u_{10}<25$ & $25 \leq u_{10}$ \\
\hline Atm. pressure, $\Delta p$ (mbar) & Surge & 1-7 days & Storm & - & $10 \leq \Delta p<60$ & $60 \leq \Delta p$ \\
\hline Sea level, $\eta_{m}(\mathrm{~m})$ & Surge & 1-7 days & Storm & - & $0.1 \leq \eta_{m} / \eta_{a}<1$ & $1 \leq \eta_{m} / \eta_{a}$ \\
\hline Significant wave height, $H_{s}(\mathrm{~m})$ & Wave action (local) & 1-7 days & Storm & - & $2 \leq H_{s}<10$ & $10 \leq H_{s}$ \\
\hline Peak period, $T_{p}(\mathrm{~s})$ & Wave action (local) & $1-7$ days & Storm & - & $7 \leq T_{p}<12$ & $12 \leq T_{p}$ \\
\hline Direction, $\theta$ & Wave action (local) & 1-7 days & Storm & - & $\mathrm{S}-\mathrm{W}$ & S-W \\
\hline$Q_{d}\left(\mathrm{~m}^{3} / \mathrm{s}\right)$ (Regulated) & River discharge & $1-4$ days & Storm, Good weather & $Q_{d}<40$ & $400<Q_{d}<3000^{\mathrm{c}}$ & $3000 \leq Q_{d}$ \\
\hline$u_{10}$ & Local wind and wave action & $12-24$ hours & Good weather & $u_{10}<7.5$ & - & - \\
\hline$\Delta p$ & Local wind and wave action & $12-24$ hours & Good weather & $\Delta p<10$ & - & - \\
\hline$H_{s}, T_{p}, \theta$ & Local wind and wave action & $12-24$ hours & Good weather & $\begin{array}{c}H_{s}<2,3 \leq T_{p}<7 \\
\text { WNW }\end{array}$ & - & - \\
\hline Sea level, $\eta_{t}(m)$ & Quake & Tsunami & $1-3$ hours & - & $\eta_{t}<1$ & $1 \leq \eta_{t}$ \\
\hline
\end{tabular}

${ }^{\mathrm{a}}$ Good weather conditions are typically normal conditions, whereas storm conditions are extreme (or exceptional) conditions.

${ }^{\mathrm{b}}$ Corresponds to the tidally-dominated regime, which is analyzed in this research study.

${ }^{\mathrm{c}}$ Corresponds to a fluvially-dominated regime, which is analyzed in this research study.

with an absolute maximum at approximately $Q_{d}=0 \mathrm{~m}^{3} / \mathrm{s}$ due to the regulation of the basin. The second (local) maximum is near $Q_{d}=20 \mathrm{~m}^{3} / \mathrm{s}$. For over $75 \%$ of the days of the year $Q_{d}$ is less than $40 \mathrm{~m}^{3} / \mathrm{s}\left(80 \%\right.$ for $\left.Q_{d}<100 \mathrm{~m}^{3} / \mathrm{s}\right)$. Based on observations and on these results, estuarine dynamics are considered to be under low-riverflow discharge conditions when $Q_{d}<40 \mathrm{~m}^{3} / \mathrm{s}$.

[23] The Estuary Number or the Canter-Cremers Number $N=Q_{d} T_{M 2} / P_{t}$, which is the ratio between the water volume discharged by the river in a semi-diurnal cycle and the tidal prism $P_{t}$ [Hansen and Rattray, 1966], ranges from $2.58 \cdot 10^{-2}$ to $5.09 \cdot 10^{-2}$ for the low-flow regime. In these conditions $N<0.1$, and the estuary is tidally dominated. The river current velocity is within the range of $1-5 \mathrm{~cm} / \mathrm{s}$, which is much lower than the maximum tidal velocities $1 \mathrm{~m} / \mathrm{s}$. The river contribution to the water level is negligible. In addition, the ratio between the water volume stored in the tidal creeks and the main channel is practically zero [Friedrichs and Aubrey, 1988].

\subsection{Harmonic Analysis of Water Elevations}

[24] A standard harmonic analysis was performed [Pawlowicz et al., 2002], which was the basis for this study of wave propagation and transformation in the estuary during the low-water, tidally-dominated regime. Specifically, the analysis period spans June 5, 2008 through December 5, 2008.

[25] It was found that $\left(\eta_{K_{1}}+\eta_{O_{1}}\right) /\left(\eta_{M_{2}}+\eta_{S_{2}}\right) \approx 0.1$, which indicates that the tide is semi-diurnal. The constituents associated with this period $\left(M_{2}, S_{2}\right.$, and $\left.N_{2}\right)$ are effectively the most energetic on the continental shelf as well as in the estuary (see Figure 4 and Table 6). They alone make up approximately $75 \%$ of the tide signal. The highest amplitudes of these constituents are reached on the shelf and at the estuary mouth. The variation in amplitudes along the closing arc in the inner continental shelf is small (Table 6). However, the constituents at the endpoints of the $\operatorname{arc}\left(\delta_{0}\right.$ and $\left.\delta_{4}\right)$ are slightly greater than the rest. From the mouth until km 20 , they decrease monotonically. Upstream in the estuary, after $\mathrm{km} \mathrm{50,} \mathrm{there} \mathrm{is} \mathrm{a} \mathrm{notable} \mathrm{increase} \mathrm{in} M_{2}$, which almost recovers the value that it had on the inner shelf. This increase is less pronounced in the case of the other two semi-diurnal constituents, despite the fact that their frequencies are similar. Their phases have a linear growth, especially between $\mathrm{km} 10$ and $\mathrm{km} 80$.

[26] The behavior of the diurnal constituents is qualitatively similar to that of the semi-diurnal constituents. At the mouth, the highest amplitudes of the group occur in the central part of the arc (station $\delta_{1}$ ), located in the prolongation of the navigation channel, whereas they decrease at the endpoints of the closing arc. The amplitude is lower at the entrance to the estuary, but in the last stretch it becomes slightly greater, particularly in the case of the constituent $O_{1}$. The other constituents of the group, $K_{1}$ and $Q_{1}$ decrease similarly to $O_{1}$, although upstream their amplitudes increase somewhat less. The growth of the phases, similarly to the semidiurnal component, is linear towards the head of the estuary.

[27] The quarter-diurnal overtides ( $M_{4}$ group) are mainly generated in the first stretch of the estuary where all of them reach a local maximum (Figure 4). The monitoring arrays installed at the mouth recorded amplitudes lower than those inside the estuary. The amplitudes decrease near $\mathrm{km} 60$, and then increase to reach their absolute maximum at the dam. These constituents contribute significantly to the tidal asymmetry and the transport and accumulation of sediments.

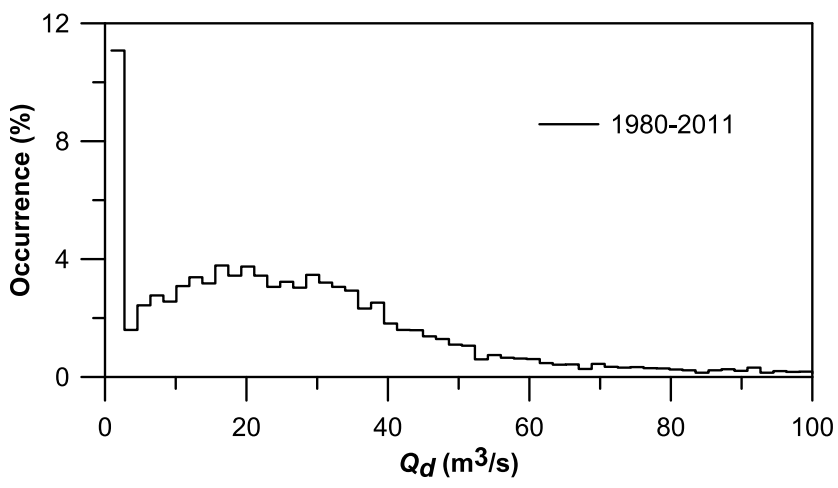

Figure 3. Probability density function of the water released by the Alcalá del Río Dam since 1980. The bin size used is $\Delta Q_{d}=2.85 \mathrm{~m}^{3} / \mathrm{s}$. 

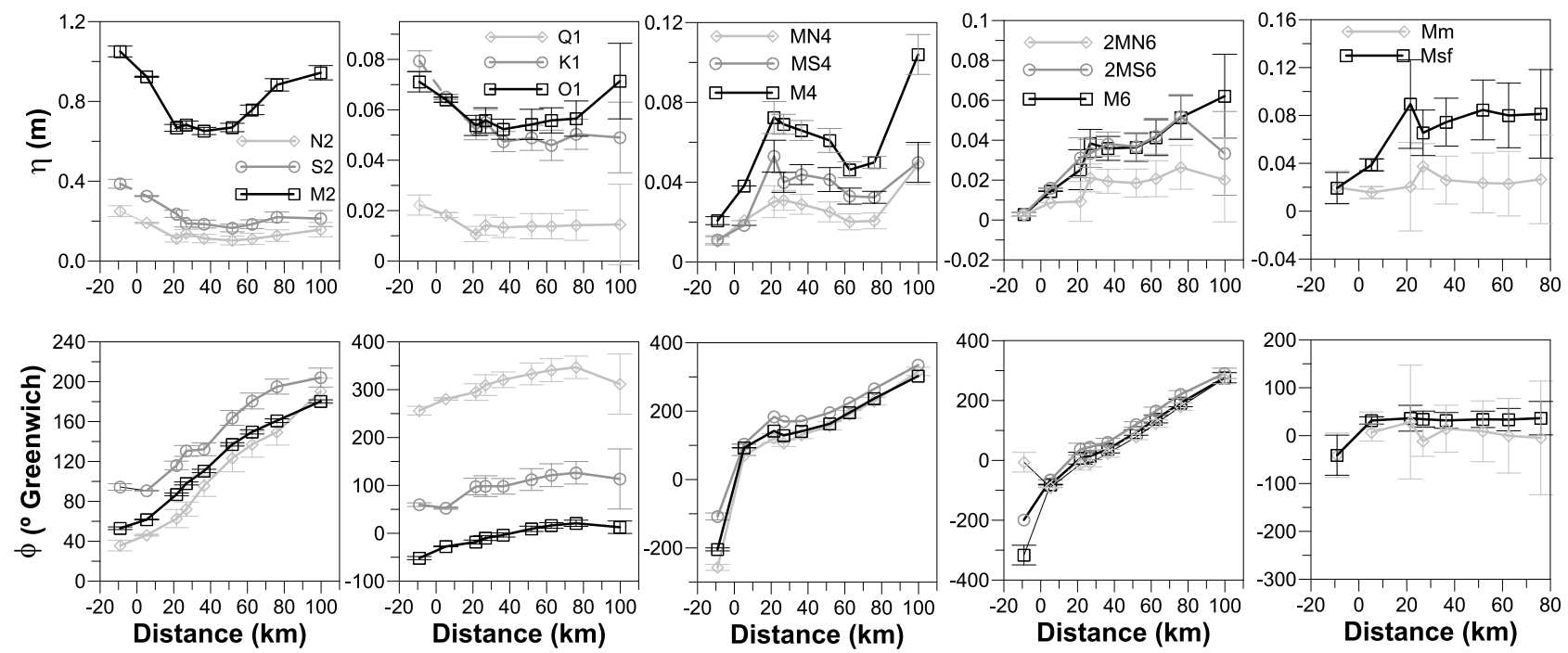

Figure 4. Longitudinal variation of the harmonic constituents of the elevations in $\mathrm{m}$. Data from $\delta_{0}, \delta_{2}, \delta_{3}$, and $\delta_{4}$ are omitted here for clarity (shown in Table 6). The error bars in amplitudes and phases represent the $95 \%$ confidence interval.

Their phases also have a linear growth inside the estuary after a sudden increase at the mouth. Sixth-diurnal overtides $\left(M_{6}\right.$, $2 M S_{6}$, and $2 M N_{6}$ ) behave similarly to the quarter-diurnal constituents, but exhibit a less marked spatial variability. The lowest amplitudes are obtained at the inner shelf due to the significant reduction in the non-linear parameter $\eta / h$ (tidal amplitude/depth). The slight hump on the increasing curves, more evident in the $M_{6}$ constituent, is located at the same section where the first order overtides show a local maximum, i.e. at section $\beta_{1}, \mathrm{~km} 21.5$. The highest amplitudes are again reached at the Alcalá del Río dam.

[28] The amplitudes of the monthly and fortnightly constituents increase at the entrance and remain uniform throughout the estuary. The phase also changes at the estuary entrance, but within the error bars, no variation was perceived with the distance. This behavior, observed in other

Table 6. Tidal Amplitudes and Phases With the 95\% Confidence Interval Estimates Derived From the Harmonic Analysis of the Water Levels $^{\mathrm{a}}$

\begin{tabular}{|c|c|c|c|c|c|c|c|c|c|c|c|c|c|c|}
\hline & $M_{2}$ & $S_{2}$ & $N_{2}$ & $K_{1}$ & $Q_{1}$ & $O_{1}$ & $M_{4}$ & $M S_{4}$ & $M N_{4}$ & $M_{6}$ & $2 M S_{6}$ & $2 M N_{6}$ & $M S_{f}$ & $M_{m}$ \\
\hline \multicolumn{15}{|c|}{ Amplitudes (cm) } \\
\hline$\delta_{0}$ & $106_{3}$ & $45.7_{2.1}$ & $20.0_{2.3}$ & $5.4_{0.5}$ & $1.5_{0.4}$ & $7.3_{0.5}$ & $2.2_{0.2}$ & $1.29_{0.10}$ & $0.87_{0.20}$ & $0.3_{0.1}$ & $0.3_{0.1}$ & $0.2_{0.1}$ & $2.2_{2.2}$ & $0.5_{1.6}$ \\
\hline$\delta_{1}$ & $105_{3}$ & $38.7_{2.2}$ & $25_{3}$ & $7.9_{0.4}$ & $2.2_{0.4}$ & $7.1_{0.4}$ & $2.10_{0.20}$ & $1.10_{0.20}$ & $1.00_{0.20}$ & $0.3_{0.1}$ & $0.3_{0.2}$ & $0.3_{0.2}$ & $1.9_{1.3}$ & $2.0_{1.4}$ \\
\hline$\delta_{2}$ & $107.0_{1.0}$ & $37.1_{1.0}$ & $22.8_{1.1}$ & $7.00_{0.20}$ & $1.70_{0.20}$ & $6.70_{0.20}$ & $2.1_{0.1}$ & $1.1_{0.1}$ & $0.9_{0.1}$ & $0.4_{0.1}$ & $0.3_{0.1}$ & $0.3_{0.1}$ & $1.3_{1.7}$ & $0.8_{1.4}$ \\
\hline$\delta_{3}$ & $103.5_{2.1}$ & $37.5_{2.1}$ & $18.7_{2.1}$ & $6.1_{0.5}$ & $1.3_{0.5}$ & $6.3_{0.5}$ & $2.2_{0.2}$ & $1.26_{0.20}$ & $0.78_{0.20}$ & $0.4_{0.2}$ & $0.3_{0.1}$ & $0.3_{0.1}$ & $1_{3}$ & $5_{4}$ \\
\hline$\delta_{4}$ & $109.8_{2.2}$ & $48_{3}$ & $21_{2}$ & $5.3_{0.6}$ & $1.6_{0.5}$ & $6.9_{0.5}$ & $2.3_{0.2}$ & $1.60_{0.20}$ & $0.90_{0.20}$ & $0.4_{0.2}$ & $0.43_{0.20}$ & $0.3_{0.2}$ & 23 & $1.4_{2.2}$ \\
\hline$\beta_{0}$ & $92.4_{0.2}$ & $32.60_{0.20}$ & $19.2_{0.3}$ & $6.51_{0.10}$ & $1.82_{0.10}$ & $6.4_{0.1}$ & $3.81_{0.01}$ & $1.84_{0.01}$ & $2.08_{0.01}$ & $1.4_{0.1}$ & $1.60_{0.05}$ & $0.87_{0.05}$ & $3.9_{0.5}$ & $1.6_{0.5}$ \\
\hline$\beta_{1}$ & $66.7_{1.7}$ & $23.7_{1.8}$ & $11.2_{1.7}$ & $5.2_{0.4}$ & $1.1_{0.3}$ & $5.4_{0.4}$ & $7.2_{0.8}$ & $5.3_{0.8}$ & $3.0_{0.8}$ & $3_{1}$ & $3.0_{0.9}$ & $0.9_{0.9}$ & $9_{4}$ & 24 \\
\hline$\beta_{2}$ & $68.2_{1.9}$ & $18.8_{1.7}$ & $13.9_{1.8}$ & $5.5_{0.5}$ & $1.4_{0.4}$ & $5.6_{0.5}$ & $6.9_{0.5}$ & $4.0_{0.6}$ & $3.1_{0.5}$ & $3.8_{0.7}$ & $3.3_{0.6}$ & $2.1_{0.6}$ & $6.6_{1.9}$ & $3.8_{1.9}$ \\
\hline$\beta_{3}$ & $65.2_{1.8}$ & $18.5_{2.0}$ & $11.3_{2.1}$ & $4.7_{0.4}$ & $1.3_{0.4}$ & $5.2_{0.4}$ & $6.6_{0.5}$ & $4.4_{0.5}$ & $2.9_{0.5}$ & $3.6_{0.60}$ & $3.8_{0.70}$ & $1.9_{0.7}$ & $7.4_{2.0}$ & $2.6_{2.0}$ \\
\hline$\beta_{4}$ & $66.9_{2.1}$ & $16.5_{1.9}$ & $10.3_{2.2}$ & $4.9_{0.5}$ & $1.4_{0.5}$ & $5.4_{0.6}$ & $6.1_{0.6}$ & $4.1_{0.5}$ & $2.5_{0.5}$ & $3.6_{0.70}$ & $3.7_{0.7}$ & $1.9_{0.7}$ & $8.5_{2.4}$ & $2_{3}$ \\
\hline$\beta_{5}$ & $75.8_{2.4}$ & $18.5_{2.2}$ & $11_{3}$ & $4.6_{0.6}$ & $1.4_{0.5}$ & $5.6_{0.5}$ & $4.6_{0.4}$ & $3.3_{0.3}$ & $2.0_{0.4}$ & $4.1_{0.9}$ & $4.2_{0.9}$ & $2.1_{0.9}$ & $8_{4}$ & 23 \\
\hline$\beta_{6}$ & $88_{3}$ & $22_{3}$ & $13_{3}$ & $5.0_{0.6}$ & $1.4_{0.6}$ & $5.7_{0.7}$ & $5.0_{0.3}$ & $3.2_{0.4}$ & $2.1_{0.4}$ & $5.1_{1.1}$ & $5_{1}$ & $3_{1}$ & $8_{6}$ & $3_{4}$ \\
\hline$\beta_{8}$ & $94_{4}$ & $21_{4}$ & $16_{4}$ & $4.9_{1.4}$ & $1.5_{1.6}$ & $7.1_{1.5}$ & $10.4_{1.0}$ & $5.0_{1.0}$ & $4.9_{1.0}$ & $6.2_{2.1}$ & $3_{2}$ & $2_{2}$ & - & - \\
\hline \multicolumn{15}{|c|}{ Phases ( ${ }^{\circ}$ Greenwich) } \\
\hline$\delta_{0}$ & $54.4_{1.3}$ & $68.9_{2.4}$ & $32_{7}$ & $47_{5}$ & $248_{17}$ & $311_{3}$ & $156_{4}$ & $229_{7}$ & $101_{13}$ & $44_{22}$ & $150_{19}$ & $350_{30}$ & $220_{60}$ & $290_{170}$ \\
\hline$\delta_{1}$ & $53.1_{1.3}$ & $94_{3}$ & $36_{5}$ & $60_{4}$ & $256_{9}$ & $308_{3}$ & $156_{4}$ & $250_{10}$ & $103_{9}$ & $40_{30}$ & $160_{30}$ & $350_{30}$ & $320_{40}$ & $310_{50}$ \\
\hline$\delta_{2}$ & $54.5_{0.6}$ & $78.2_{1.6}$ & $37_{3}$ & $49_{2}$ & $256_{7}$ & $308.9_{1.6}$ & $157_{3}$ & $243_{6}$ & $104_{7}$ & $55_{16}$ & $150_{17}$ & $6_{15}$ & $300_{80}$ & $310_{130}$ \\
\hline$\delta_{3}$ & $52.2_{1.1}$ & $59_{3}$ & $39_{6}$ & $34_{4}$ & $247_{21}$ & $308_{4}$ & $156_{4}$ & $229_{7}$ & $101_{13}$ & $39_{20}$ & $140_{20}$ & $352_{24}$ & $270_{150}$ & $190_{50}$ \\
\hline$\delta_{4}$ & $54.8_{1.2}$ & $70_{3}$ & $33_{6}$ & $53_{5}$ & $243_{16}$ & $313_{4}$ & $163_{5}$ & $243_{7}$ & $95_{13}$ & $50_{20}$ & $154_{22}$ & $340_{30}$ & $230_{70}$ & $280_{110}$ \\
\hline$\beta_{0}$ & $61.74_{0.13}$ & $90.7_{0.4}$ & $46.2_{0.8}$ & $52.7_{0.7}$ & $280.6_{2.4}$ & $332.5_{0.7}$ & $92.8_{0.4}$ & $103.9_{0.9}$ & $70.2_{0.8}$ & $279.0_{0.6}$ & $294.8_{0.6}$ & $270_{1}$ & $32_{8}$ & $7_{18}$ \\
\hline$\beta_{1}$ & $87.0_{1.4}$ & $116_{4}$ & $63_{9}$ & $98_{4}$ & $295_{17}$ & $342_{4}$ & $142_{7}$ & $184_{8}$ & $121_{13}$ & $7_{20}$ & $38_{18}$ & $350_{50}$ & $40_{30}$ & $30_{120}$ \\
\hline$\beta_{2}$ & $100.0_{1.5}$ & $131_{5}$ & $72_{7}$ & $98_{5}$ & $310_{22}$ & $350_{5}$ & $129_{4}$ & $170_{7}$ & $110_{10}$ & $14_{11}$ & $45_{11}$ & $350_{21}$ & $34_{17}$ & $350_{30}$ \\
\hline$\beta_{3}$ & $110.5_{1.7}$ & $132_{6}$ & $96_{11}$ & $98_{5}$ & $321_{16}$ & $356_{4}$ & $141_{5}$ & $171_{6}$ & $130_{11}$ & $38_{13}$ & $61_{10}$ & $24_{20}$ & $32_{17}$ & $10_{50}$ \\
\hline$\beta_{4}$ & $137.2_{1.7}$ & $164_{7}$ & $123_{14}$ & $112_{7}$ & $333_{23}$ & $9_{6}$ & $160_{6}$ & $196_{7}$ & $157_{12}$ & $93_{9}$ & $120_{10}$ & $78_{26}$ & $34_{17}$ & $10_{60}$ \\
\hline$\beta_{5}$ & $149.7_{2.1}$ & $181_{8}$ & $137_{13}$ & $121_{7}$ & $341_{24}$ & $16_{6}$ & $196_{5}$ & $224_{6}$ & $191_{11}$ & $138_{13}$ & $166_{12}$ & $120_{30}$ & $33_{23}$ & $360_{80}$ \\
\hline$\beta_{6}$ & $160.9_{1.9}$ & $195_{8}$ & $149_{13}$ & $126_{7}$ & $347_{23}$ & $21_{7}$ & $237_{4}$ & $265_{7}$ & $229_{11}$ & $192_{12}$ & $221_{11}$ & $180_{22}$ & $36_{30}$ & $360_{120}$ \\
\hline$\beta_{8}$ & $180.3_{1.5}$ & $200_{10}$ & $190_{13}$ & $110_{20}$ & $310_{60}$ & $13_{13}$ & $300_{7}$ & $335_{12}$ & $316_{12}$ & $276_{17}$ & $290_{40}$ & $270_{50}$ & - & - \\
\hline
\end{tabular}

${ }^{\mathrm{a}}$ The subscript indicates the error in the last significant figure. 
Table 7. Results of the Harmonic Analysis of the Along-Channel Horizontal Tide ${ }^{\mathrm{a}}$

\begin{tabular}{|c|c|c|c|c|c|c|c|c|c|c|c|c|c|c|}
\hline & $M_{2}$ & $S_{2}$ & $N_{2}$ & $K_{1}$ & $Q_{1}$ & $O_{1}$ & $M_{4}$ & $M S_{4}$ & $M N_{4}$ & $M_{6}$ & $2 M S_{6}$ & $2 M N_{6}$ & $M S_{f}$ & $M_{m}$ \\
\hline \multicolumn{15}{|c|}{ Amplitudes (cm) } \\
\hline$\alpha_{0}$ & $63_{7}$ & $20_{6}$ & $7_{6}$ & $5_{3}$ & $1_{2}$ & $3_{3}$ & $5_{2}$ & $4_{3}$ & $2_{3}$ & $3.0_{1.6}$ & $3.5_{1.4}$ & $1.4_{1.5}$ & 24 & $1_{4}$ \\
\hline$\alpha_{1}$ & $100_{5}$ & $35_{5}$ & $12_{6}$ & $4.0_{1.1}$ & $1_{1}$ & $4.9_{1.1}$ & $3.9_{1.3}$ & $4.2_{1.3}$ & $1.8_{1.2}$ & $4.1_{1.7}$ & $5.8_{1.8}$ & $2.9_{1.9}$ & $4_{3}$ & $1.1_{2.2}$ \\
\hline$\alpha_{2}$ & $50_{6}$ & $14_{7}$ & 36 & $9_{7}$ & $1_{5}$ & $9_{6}$ & 23 & $3_{3}$ & $1_{2}$ & $3.3_{1.7}$ & $4.7_{1.8}$ & $1.5_{1.7}$ & $4_{5}$ & $3_{4}$ \\
\hline$\alpha_{3}$ & 694 & $222_{4}$ & $8_{4}$ & $2.3_{0.5}$ & $0.7_{0.5}$ & $3.3_{0.4}$ & $5.1_{1.2}$ & $3.4_{1.1}$ & $1.0_{1.2}$ & $5_{3}$ & $7.2_{2.4}$ & $2.1_{2.1}$ & $1.7_{1.3}$ & $0.9_{1.2}$ \\
\hline$\alpha_{4}$ & $72_{3}$ & $23_{3}$ & 84 & $4.1_{2.4}$ & $0.6_{1.9}$ & $2.4_{2.4}$ & $4.0_{2.3}$ & $3.6_{2.3}$ & $3_{3}$ & $8_{3}$ & $11_{3}$ & $3_{3}$ & $3_{3}$ & 23 \\
\hline$\alpha_{5}$ & $55_{3}$ & $18_{3}$ & $6_{3}$ & $1.6_{0.7}$ & $0.8_{0.7}$ & $2.7_{0.7}$ & $8.5_{2.0}$ & $7.8_{1.7}$ & $2.8_{1.7}$ & $8_{3}$ & $10_{3}$ & $3_{3}$ & $2.2_{1.1}$ & $0.7_{0.9}$ \\
\hline \multicolumn{15}{|c|}{ Phases $\left({ }^{\circ}\right.$ Greenwich $)$} \\
\hline$\alpha_{0}$ & $54_{5}$ & $79_{17}$ & $30_{50}$ & $60_{40}$ & $290_{130}$ & $220_{60}$ & $100_{30}$ & $120_{40}$ & $70_{70}$ & $22_{30}$ & $26_{21}$ & $330_{60}$ & $250_{140}$ & $350_{180}$ \\
\hline$\alpha_{1}$ & $63_{3}$ & $80_{9}$ & $20_{30}$ & 3716 & $240_{90}$ & $285_{13}$ & $100_{20}$ & $97_{18}$ & $70_{40}$ & $70_{24}$ & $74_{18}$ & $13_{40}$ & $230_{40}$ & $190_{120}$ \\
\hline$\alpha_{2}$ & $69_{9}$ & $110_{30}$ & $60_{120}$ & $60_{40}$ & $200_{300}$ & $220_{50}$ & $150_{60}$ & $160_{50}$ & $120_{110}$ & $60_{30}$ & $84_{19}$ & $50_{60}$ & $300_{90}$ & $90_{100}$ \\
\hline$\alpha_{3}$ & $77_{3}$ & $104_{9}$ & $40_{30}$ & $24_{12}$ & $260_{40}$ & $284_{9}$ & $250_{12}$ & $272_{21}$ & $190_{70}$ & $90_{30}$ & $124_{20}$ & $40_{80}$ & $180_{50}$ & $210_{80}$ \\
\hline$\alpha_{4}$ & $85_{3}$ & $112_{8}$ & $70_{30}$ & $30_{40}$ & $170_{160}$ & $320_{50}$ & $250_{30}$ & $230_{30}$ & $180_{50}$ & $120_{23}$ & $151_{15}$ & $80_{80}$ & $230_{90}$ & $230_{110}$ \\
\hline$\alpha_{5}$ & $90_{3}$ & $122_{8}$ & $60_{30}$ & $70_{30}$ & $240_{60}$ & $278_{16}$ & $196_{13}$ & $234_{13}$ & $180_{40}$ & $150_{22}$ & $175_{16}$ & $120_{60}$ & $50_{30}$ & $0_{80}$ \\
\hline
\end{tabular}

${ }^{\text {a }}$ The subscript indicates the error as in Table 6.

estuaries, is due to the frequency-dependent response of the estuary. Prandle and Rahman [1980] developed a linear theory for one-dimensional tidal propagation which shows that for frequencies lower than diurnal a low response occurs when the tide propagates upstream, whereas shorter period harmonics may exhibit a significant amplification.

\subsection{Harmonic Analysis of Along-Channel Currents}

[29] In the same way as the water level, the greatest contribution to the tidal current comes from constituents $M_{2}$ and $S_{2}$ (Table 7 and Figure 5). These constituents have two local maxima near $\mathrm{km} 20$ and $\mathrm{km} \mathrm{50.} \mathrm{The} \mathrm{growth} \mathrm{of} \mathrm{the} \mathrm{phases} \mathrm{of}$ the semidiurnal constituents is linear, like that of the water levels. The diurnal constituents, $K_{1}$ and $O_{1}$, achieve a maximum at $\mathrm{km} 30$, although they tend to decrease upstream. Their phases vary more slowly than the phases of the semi-diurnal group. The quarter-diurnal overtides attain their maxima at $\mathrm{km}$ 60. This position coincides with a local water level minimum for these harmonics (Figure 4). Their phases grow until $\mathrm{km} \mathrm{40,} \mathrm{after} \mathrm{which} \mathrm{it} \mathrm{stabilizes.} \mathrm{Sixth-diurnal} \mathrm{amplitudes,} \mathrm{of}$ the same order of magnitude as the quarter-diurnal overtides, behave similarly. The monthly and fortnightly constituents, within the margin of the error bars, decrease slightly towards the head of the estuary.

\subsection{Tidal Asymmetry}

[30] As the tide propagates into shallower waters, nonlinear effects become important, and the wave profile distorts. The crest of the tide may partially overtake the trough, resulting in a shorter flood and a longer ebb. The highest velocities thereby occur during the flood tide. This tidal asymmetry can be due to the production of even harmonics from the $M_{2}$ tide. Figure 6 shows the ratio of the $M_{4}$ and $M_{2}$ amplitudes, $\eta_{M_{4}} / \eta_{M_{2}}$. When the tide enters the estuary, this ratio increases considerably from 0.02 to 0.10 . Its local maximum occurs in the first stretch, approximately at $\mathrm{km} 20$. Afterwards, it decreases until $\mathrm{km} 60$, and finally reaches its overall maximum of 0.11 at the dam. These values are similar to the ratios obtained for many other estuaries. Friedrichs and Aubrey [1988] analyzed the water level in 26 tidally dominated estuaries all along the USA Atlantic Coast and the values they obtained rarely exceeded 0.15 . Blanton et al. [2002], in their study on the tidal current asymmetry, gave for a $100 \mathrm{~km}$ long coastal plain estuary (the Satilla River estuary)
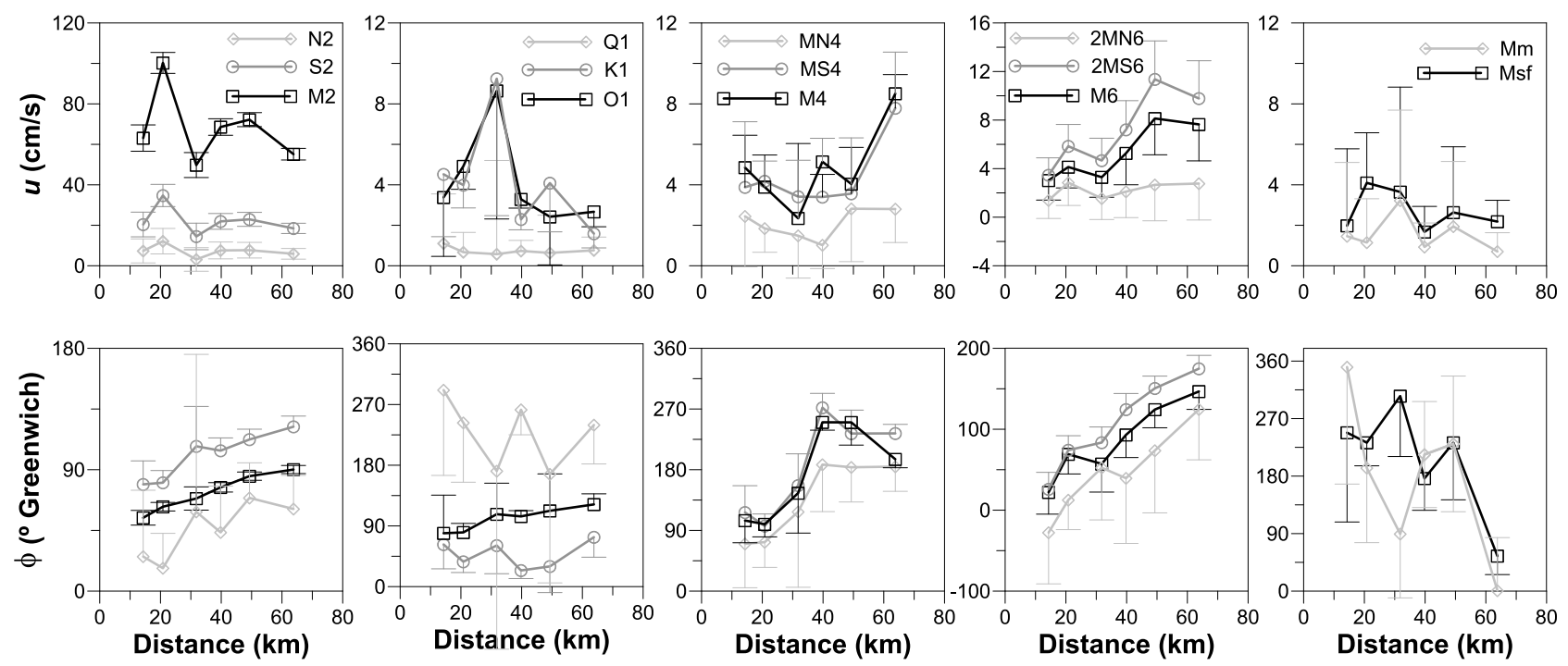

Figure 5. Longitudinal variation of the harmonic constituents for the along-channel velocity. As in Figure 4, error bars represent the $95 \%$ confidence interval. 

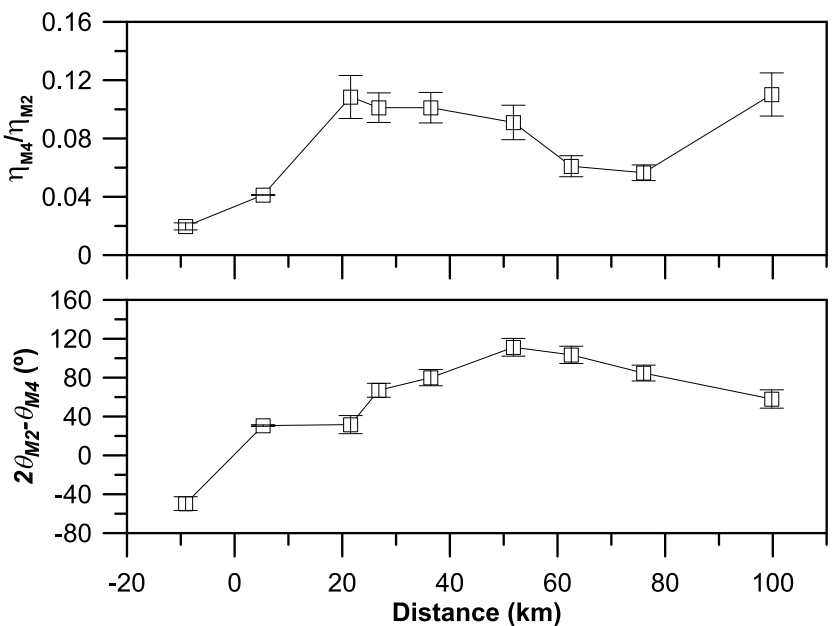

Figure 6. (top) The amplitude ratio $\eta_{M_{4}} / \eta_{M_{2}}$ and (bottom) the elevation phase difference $12 \theta_{M_{2}}-\theta_{M_{4}} \mid$.

values ranging from 0.05 to 0.17 . Higher ratios are usually observed in tidal creeks and tidal flats. On the other hand the difference between phases, $12 \theta_{M_{2}}-\theta_{M_{4}} \mid$ is less than $180^{\circ}$ throughout the estuary (Figure 6), which indicates that the estuary is flood-dominant according to Speer and Aubrey [1985]. This behavior is also found in other channeled estuaries with a small surface of tidal flats [see, e.g., Friedrichs and Madsen, 1992; Friedrichs and Aubrey, 1994; Blanton et al., 2002].

\subsection{Spring and Neap Tide Cycles}

[31] The importance of spring and neap tide cycles in tidal dynamics is shown in Figure 7. Figure 7 (top) shows the longitudinal variation of the tidal amplitude $\eta$ both in spring
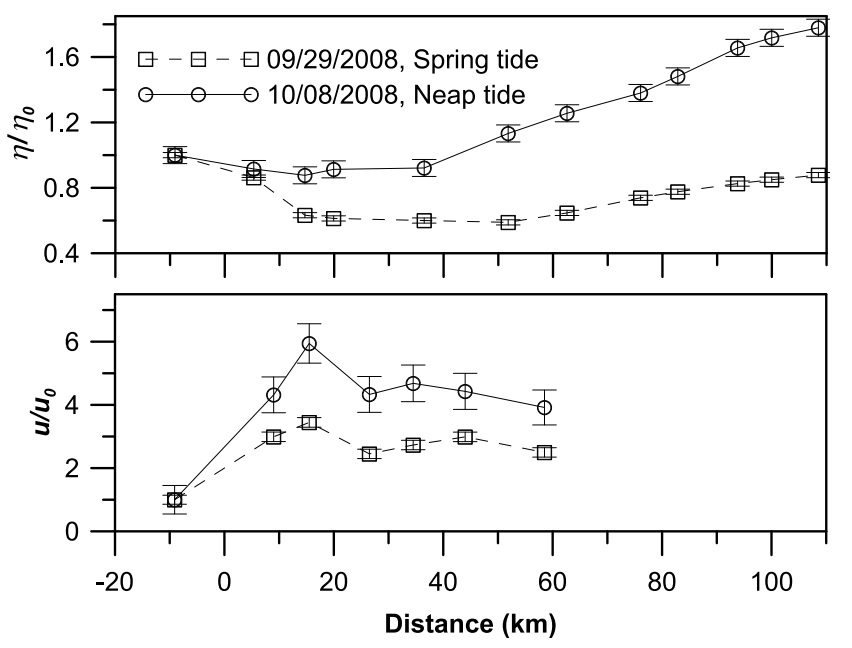

Figure 7. (top) Normalized tidal amplitude in spring and neap tides. The spring and neap tide amplitudes at the mouth are respectively, $\eta_{0}=316 \mathrm{~cm}$ and $\eta_{0}=97 \mathrm{~cm}$. (bottom) Normalized current amplitude in the same dates. The spring and neap tidal current amplitudes are, respectively, $u_{0}=36 \mathrm{~cm} / \mathrm{s}$ and $u_{0}=12 \mathrm{~cm} / \mathrm{s}$. Error bars are associated to the measurement uncertainty.

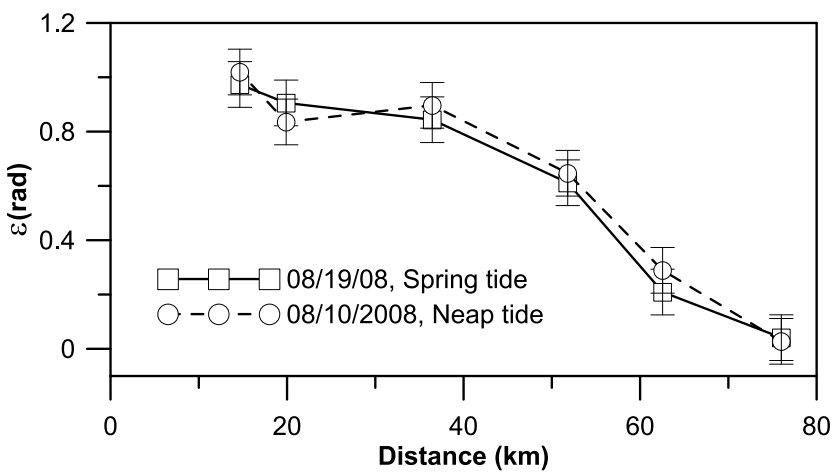

Figure 8. Phase lag $\varepsilon$ between the high water and the highwater slack in the estuary in spring tides as well as neap tides. Error bars are the current-meters sampling period (15 min) expressed in radians.

and neap tides nondimensionalized by their respective values at the estuary mouth. In the first stretch of the estuary, the tidal range is reduced in comparison to its range in the open sea. This reduction is more significant in spring tides $(40 \%)$ than in neap tides $(10 \%)$. The amplitudes do not experience any significant change in the middle stretch of the estuary. This is even more evident in spring tides. Figure 7 highlights the fact that after $\mathrm{km} \mathrm{50,} \mathrm{the} \mathrm{amplitude} \mathrm{monotonically}$ increases until the dam. During spring tides (squares), the amplitudes regain almost the same value that they had at the mouth. During neap tides (circles), they increase up to $60 \%$.

[32] Figure 7 (bottom) shows the spatial evolution of the along-channel current $u$ in spring (squares) and neap tides (circles). Notice that currents are normalized with respect to their respective values at the estuary mouth. The amplitude of the currents recorded on the inner shelf is on the order of $30 \mathrm{~cm} / \mathrm{s}$ for spring tides (squares) and $10 \mathrm{~cm} / \mathrm{s}$ for neap tides (circles). In the first $15 \mathrm{~km}$ of the estuary, the tidal velocity increases, exceeding $1 \mathrm{~m} / \mathrm{s}$ in spring tides. After this increase, the general tendency of currents is to decrease upstream with a local maximum near $\mathrm{km} 45$. Furthermore, there is a notable difference in the current amplitudes (though not in phases) between spring and neap tides. Current velocity in spring tides almost doubles the velocity of neap tides.

\subsection{Oscillatory Motion of the Tide}

[33] The oscillatory motion is also characterized in terms of phase lag $\varepsilon$ between the high water and the high-water slack [Dyer, 1997]. At the edge of the continental shelf, the tidal motion is progressive co-oscillating. When the tide enters the estuary (Figure 8) it experiences an additional phase lag because of friction, which is close to but less than the value of $\pi / 4$ obtained under the frictional dominance assumption (zero-inertia approximation) [Friedrichs and Madsen, 1992; Dronkers, 2005]. This, along with the damping of the tidal elevation, suggests that the tidal motion in the first kilometers is frictionally-dominated. The phase lag decreases further upstream, and becomes practically zero at $\mathrm{km} 80$. This occurs in both spring and neap tides (Figure 8). This indicates that in the upper third of the estuary, the tidal propagation is partially standing due to the reflection on the dam, which acts 

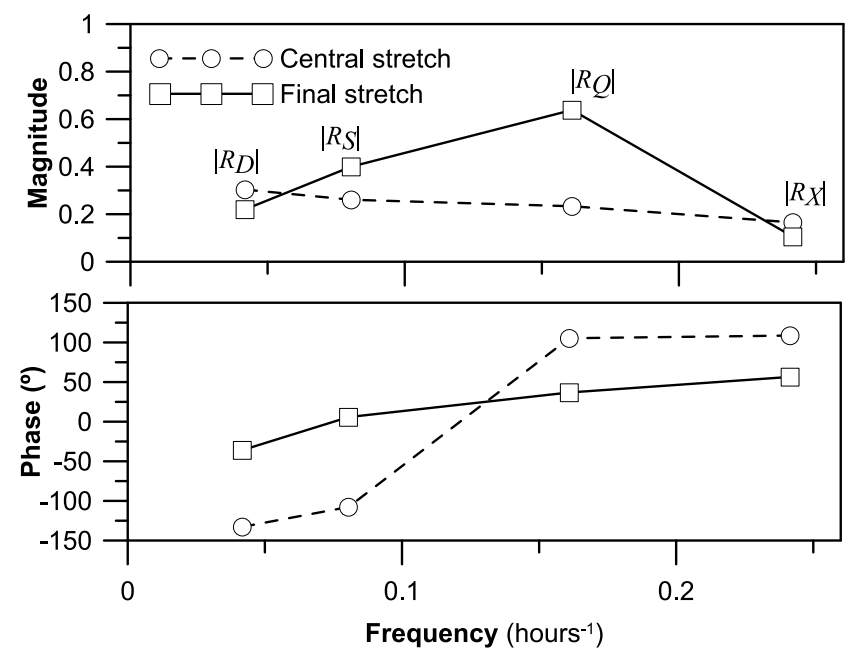

Figure 9. Phase and magnitude of the frequency-dependent reflection coefficient $R$ for the two sets of tidal gauges.

as a punctual reflector. The reflected waves travel to the mouth, undergoing inverse shoaling and dissipation.

\section{Linear Analysis of Tidal Reflection at the Dam}

[34] The results of the harmonic analysis do not provide the reflection coefficient and the phase of each constituent. To separate the incident from the reflected wave and calculate the complex reflection coefficient $R$, a method based on the least squares fitting technique was applied [Baquerizo, 1995]. Details are given in Appendix A. For this purpose, two water level data sets were used. The first one corresponds with $\beta_{7}, \beta_{8}$, and $\beta_{9}$, located close to the dam, at a distance of less than $15 \mathrm{~km}$. The second set of tidal gauges $\left(\beta_{3}, \beta_{4}\right.$, and $\left.\beta_{5}\right)$ were located in the central stretch of the estuary at a distance of $60-80 \mathrm{~km}$ from the dam. This method requires that the three sensors measure the same wave, and therefore, that its amplitude, length and phase are not modified by variations in the width and depth of the channel or by dissipation because of friction with the bottom and margins. The analysis was carried out over a period of 35 days (from July 15, 2010 to August 19, 2010) during low-riverflow conditions.

[35] Although both the incident and reflected wave suffer shoaling (inverse shoaling for the reflected wave) and friction dissipation, the location of the first set of tidal gauges is closest to the ideal. The head of the estuary is not part of the navigation channel, and thus, it is not dredged. This means that the channel width and depth are relatively uniform. Furthermore, the distance between the three tidal gauges over the last $15 \mathrm{~km}$ is much less than the wavelength of the most significant tidal components, even of the quarterdiurnal ones. Consequently, in an initial approach, the wave measured by the first set of three gauges can be regarded as uniform without significant error.

[36] The second set of tidal gauges is far from the main source of reflection and placed where the tidal amplitudes do not vary significantly, because dissipation and shoaling (including inverse shoaling) of the diurnal and semidiurnal components are in balance. Furthermore, the overtides contain less energy than that observed in the first set of tidal gauges. For all these reasons, the results obtained from the analysis of the second set of tidal gauges should be considered with caution.

[37] Figure 9 shows the reflection coefficient values, $R$, obtained for the two data sets. The reflection coefficient varies with the frequency. For the tidal gauges closest to the dam, $R$ exhibits its maximum for the quarter-diurnal tides (for $\left.M_{4},\left|R_{Q}\right| \approx 0.65\right)$. Smaller values are obtained for the semidiurnal (for $M_{2},\left|R_{S}\right| \approx 0.40$ ) and diurnal (for $K_{1},\left|R_{D}\right| \approx 0.25$ ) constituents. The reflection coefficient has a minimum value for the sixth-diurnal constituents (for $M_{6},\left|R_{X}\right| \approx 0.10$ ). For the set placed at a greater distance from the dam, the reflection coefficient at diurnal and sixth-diurnal frequencies increases slightly $\left(\left|R_{D}\right| \approx 0.30\right.$, and $\left|R_{X}\right| \approx 0.15$, respectively), whereas the coefficient of the semidiurnal constituents decreases $\left(\left|R_{S}\right| \approx 0.25\right)$, and that of the quarter-diurnal components decreases even more significantly $\left(\left|R_{Q}\right| \approx 0.20\right)$.

[38] The decrease in the reflection coefficients observed at the central stretch for semidiurnal and quarter diurnal components is not surprising because of inverse shoaling and the dissipation experienced by the wave reflected at the dam. The slight increase for the diurnal and sixth-diurnal tides could be due to additional reflection at the meanders and to changes in depth, however differences lie within the expected margins of error associated to the values obtained for the central part.

[39] The frequency-dependent reflection coefficient spatially varies with the absolute distance to the reflector, because of the increase in the dissipation and inverse shoaling of the reflected wave. This behavior is not an exclusive attribute of the tides. It has been found in the propagation of gravity waves in dissipative and reflecting systems, such as beaches [Wright and Short, 1983; Tatavarti et al., 1988; Baquerizo et al., 1997, 1998] and porous media [Losada et al., 1993].

[40] As happens with other phenomena, such as river discharge, horizontal density gradient, and asymmetry in tidal mixing [Cheng et al., 2011], the tidal reflection can generate residual currents that have consequences in the bed morphology. Close to the bottom, the partially standing motion induces a net mass transport velocity inside the boundary layer [Longuet-Higgins, 1953] that is composed of two terms, the Eulerian drift and the Stokes drift (see Appendix B). The horizontal gradient of this net horizontal velocity gives a clue of the bed erosion-deposition patterns. For the relatively fine particles of the estuary, the dominant sediment transport mode is suspension. Then bars tend to form in the antinodes, whereas bed erosion occurs in the nodes.

[41] Figure 10 shows the net mass transport velocity (Figure 10, top) and its gradient (Figure 10, middle) along the upper stretch of the estuary for constituents $M_{2}$ and $M_{4}$, calculated with the reflection coefficients obtained with the first set of tidal gauges (Figure 9). The reflection of the $M_{4}$ component favors sedimentation in the area near the dam, and the reflection of the $M_{2}$ component extends possible sedimentation to the area near the entrance to the Port of Seville, where the Port Authority of Seville dredges with greater frequency and intensity (see Figure 10). It is necessary to mention that the kinetic energy of the $M_{4}$ constituent is about $7-15 \%$ of the one that corresponds to $M_{2}$. Thus, the effect of the $M_{2}$ component would be dominant and explains by itself the large amount of sediment dredged. This 

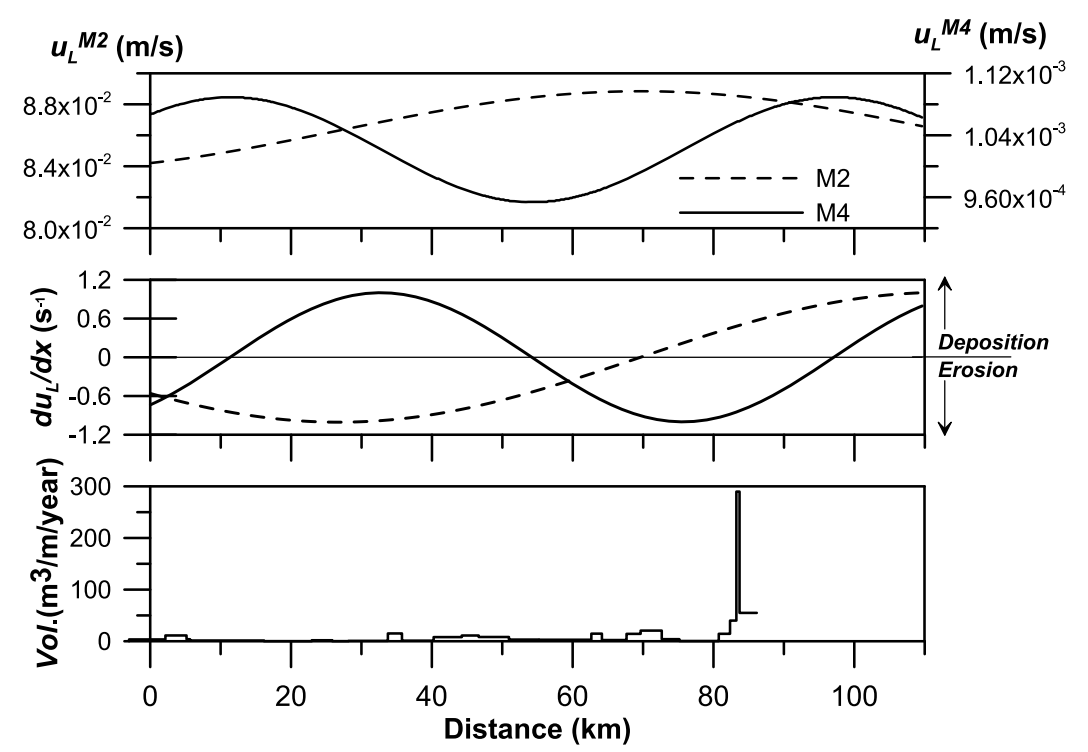

Figure 10. (top) Mass transport velocity and (middle) its longitudinal gradient. (bottom) Mean annual dredged volume $\left(\mathrm{m}^{3} / \mathrm{m} / \mathrm{yr}\right)$ provided by the Port Authority of Seville. The largest amount of dredging occurs at $\mathrm{km} 25$ from the dam.

morphological pattern can be altered by other residual currents, possibly moving the position of the bars and holes downstream. In addition, because of the expected reduction of the importance of reflection on the tide oscillation with the distance to the dam, the bed pattern obtained from $\mathrm{km} 70$ to the mouth (see Figure 10) should be regarded as indicative.

\section{Process-Based Zonation of the Guadalquivir Estuary}

[42] The tidal propagation along the Guadalquivir estuary, which is tidally-dominated and well-mixed during low river flow, basically depends on the following: (1) estuary geometry, mainly given by section and depth variations; (2) reflection on the Alcalá del Río dam at the head (and possibly on abrupt section changes); and (3) friction at the boundaries. These factors govern the spatial evolution of the tidal amplitude, the wave celerity and the phase lag between vertical and horizontal tides [Jay, 1991; Friedrichs and Aubrey, 1994; Lanzoni and Seminara, 1998; Prandle, 2003, 2004; Savenije and Veling, 2005].

[43] The previous results suggest that, without considering the inner shelf zone where the propagation is progressively co-oscillating, the estuary can be divided into three stretches based on morpho-hydrodynamic similarities and on the dominant tidal processes (see Figure 1).

[44] The first extends from the mouth and entrance of the estuary $(\mathrm{km} 0)$ to $\mathrm{km} \mathrm{25}$, approximately (Figure 1). Along this stretch, the amplitude of the sea level decreases, as can be observed in the spatial evolution of the most energetic constituents, namely, the semidiurnal and diurnal ones, that absorb most of the observed damping (see Figure 4). Several mechanisms may be responsible for this behavior, e.g., the secondary circulation, important in curves with a small radius and meanders, and the rapid exchange flow at the mouth. The momentum exchange with the tidal flats (seen as storage areas), albeit small, may also play a role. Further studies should be carried out to identify and quantify them.

[45] The analysis of the one-dimensional momentum equation (equation (C3) in Appendix C) in the stretch nearest to the mouth shows that the order of magnitude of the horizontal pressure gradient, $g(\eta+h) \partial \eta / \partial x$, is $1.99 \cdot 10^{-3} \mathrm{~m}^{2} / \mathrm{s}^{2}$. The friction term is of the same order as this one, $\sim 10^{-3} \mathrm{~m}^{2} / \mathrm{s}^{2}$, and dominates over the inertial terms, whose amplitudes do not exceed $2 \cdot 10^{-4} \mathrm{~m}^{2} / \mathrm{s}^{2}$. The barotropic density gradient does not contribute significantly to the momentum equation, $\approx 6 \cdot 10^{-5} \mathrm{~m}^{2} / \mathrm{s}^{2}$.

[46] This diffusive behavior can be quantitatively described in terms of a diffusion equation for elevations that results from the assumption that friction dominates over inertial acceleration. Under the zero-inertia approximation, combining the one-dimensional momentum and continuity equations, and considering a quadratic shear stress with a friction drag coefficient $C_{D} \approx 2.5 \cdot 10^{-3}$ (computed below in this section), a non-linear diffusion equation is obtained [Friedrichs and Madsen, 1992; Lanzoni and Seminara, 1998; Dronkers, 2005]. The equation reads $\eta_{t}=\kappa \eta_{x x}$, where $\kappa=g h^{2} /$ $\left(2 C_{D}|u|\right), g$ is the acceleration of gravity, $h$ the mean water depth, $u$ the along-channel velocity, and the subscripts indicate partial derivatives. The diffusion coefficient $\kappa$ varies during the tidal period, in particular because of its dependence on $u$. However, as a first approximation, a time-independent value for $\kappa$ is adopted here. For the first $L_{0}=25 \mathrm{~km}$, and computing the root mean square value of the current associated to the semidiurnal component in $\alpha_{0},|u|_{\text {r.m.s. }} \approx 0.5 \mathrm{~m} / \mathrm{s}$, a value of $\kappa=1.92 \cdot 10^{5} \mathrm{~m}^{2} / \mathrm{s}$ is obtained. The characteristic time of the tidal diffusion process, $\tau$, provided by the scaled diffusion equation that is obtained for the adopted value of $\kappa$, is $\tau=L_{0}^{2} / \kappa \approx 0.91$ hours, which is much smaller than the semi-diurnal dominant temporal scale, namely, $T_{M 2}=12.45$ hours. This result is consistent with a rapid decay of the elevations at the entrance of the estuary (see Figure 4, $M_{2}$ elevations, and Figure 7, top). 

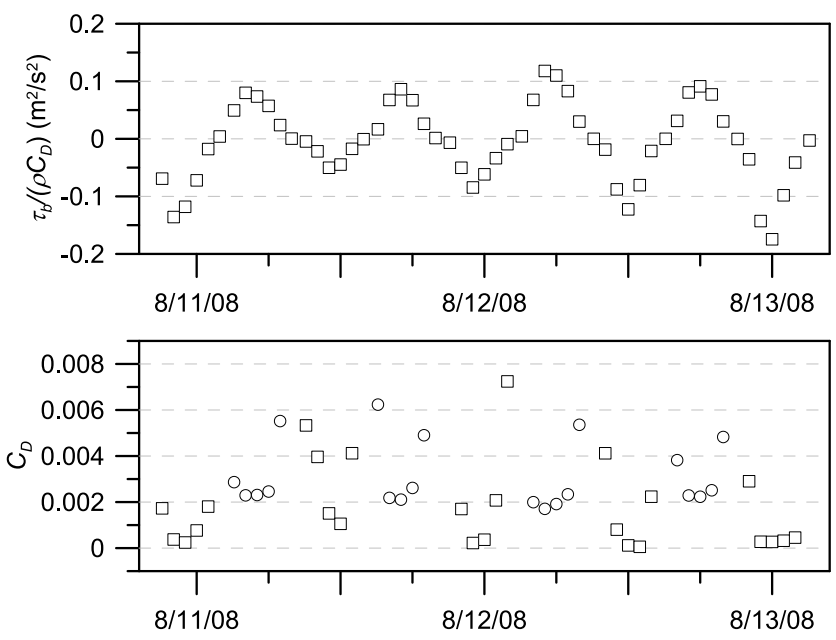

Figure 11. (top) Relation between the bottom shear stress $\tau_{b}$ and the drag coefficient $C_{D}$. (bottom) Temporal evolution of $C_{D}$ during several flood (circles) and ebb (squares) cycles measured between tidal gauges $\beta_{3}$ and $\beta_{4}$.

[47] In the following $35 \mathrm{~km}$ (the second stretch, Figure 1), the amplitude of the sea level does not substantially vary as shown in the diurnal and semi-diurnal principal constituents (Figure 4). This behavior suggests that channel convergence and friction are in balance [Dyer, 1997; Savenije and Veling, 2005]. As the tide propagates, the amount of energy per unit width lost by friction equals the amount of energy gained by channel convergence which may explain why the tidal range along the estuary axis is constant. This leads to a reduction of the elevations gradient term $g(\eta+h) \partial \eta / \partial x$ by a factor of 10 (see equation (C3)), resulting in a value which amplitude is approx. $1.8 \cdot 10^{-4} \mathrm{~m}^{2} / \mathrm{s}^{2}$ in the central zone of the estuary. The acceleration terms, $\partial((\eta+h) \underline{u}) / \partial t$ and $u(\eta) \partial \eta / \partial t$, which account for the explicit dependence on time, become increasingly relevant and attains the same order of magnitude as the previous one, i.e. $\approx 1.2 \cdot 10^{-4} \mathrm{~m}^{2} / \mathrm{s}^{2}$. The density gradient is again the less efficient momentum generating mechanism, with a value $g(\eta+h)^{2} /(2 \rho) \cdot \partial \rho / \partial x \approx 3.8 \cdot 10^{-5} \mathrm{~m}^{2} / \mathrm{s}^{2}$.

[48] The along-channel drag coefficient $C_{D}$ was determined following Geyer et al. [2000] (see details in Appendix C). Figure 11 shows the temporal evolution of the bottom shear stresses $\tau_{b}$ as well as of $C_{D}$. The result is representative of the middle third of the estuary, specifically between sections $\beta_{3}$ and $\beta_{4}$. Instantaneous values of $C_{D}$ represented with circles in Figure 11 correspond with flood tide, and values with squares correspond with ebb tide. In slack water, the velocity was zero and $C_{D}$ cannot be computed. The range of tidallyaverage values obtained, $2.5 \cdot 10^{-3} \leq C_{D} \leq 5 \cdot 10^{-3}$, is similar to those obtained in other estuarine environments [Geyer et al., 2000; Dronkers, 2005; Scully and Friedrichs, 2007], despite the restrictions imposed by the available measurements and the hypotheses adopted.

[49] The last (third) zone of approximately $50 \mathrm{~km}$ in length is dominated by the reflection on the Alcalá del Río dam (Figure 1). Wave reflection at the head is not an exceptional situation [Blanton et al., 2002; Geyer and Chant, 2006]. However, as has been shown in the previous sections, the prominent wave reflection has a significant impact on the dynamics and morphology. In this research, reflection has been characterized on the basis of water level measurements (Figure 4), the phase lag between high water and high-water slack (Figure 8), and the frequency-dependent reflection coefficient (Figure 9).

\section{Fluvially-Dominated Regime}

[50] The passage of storms from the Atlantic Ocean substantially modify the magnitude of winds, wave action, mean water level, and possibly river discharges (see details in Table 5). These storms last on a scale of 1-7 days (synoptic meteorological scale) and can occur several times each year. The number of storms per year and the total annual rainfall on the Guadalquivir watershed produced by these events show a periodicity of 12 years [Ávila, 2007]. In cycles of rainy years, the North Atlantic Oscillation Index, $n$, is negative and its absolute value is greater than 20; in cycles of dry years, $n$ is positive, between 0 and 5 [Prieto et al., 2009].

[51] Freshwater discharges from the dam, regardless of whether they are accompanied by precipitation, occur on a synoptic scale during the passage of South Atlantic storms. These discharges are typically greater than $400 \mathrm{~m}^{3} / \mathrm{s}$. In these conditions, the estuary is no longer dominated by the tide, and becomes fluvially-dominated. The fluvial current is of the same order or larger than the maximum tidal velocities, and much greater than the low-frequency, residual tidal currents. Fresh water then dominates the estuary and a substantial part of the inner shelf. The form and magnitude of the discharge are variable since they depend on the meteorological and oceanographic conditions at the mouth and the inner continental shelf, and especially on the regulatory system of the Guadalquivir river basin.

[52] Figure 12 shows the daily averaged river discharge released by the Alcalá dam into the estuary during the period $12 / 18 / 09-01 / 05 / 10$. Most of the time the discharges were greater than $800 \mathrm{~m}^{3} / \mathrm{s}$ with peaks close to $2000 \mathrm{~m}^{3} / \mathrm{s}$. The estuary number $N$ is much larger than under low-flow conditions, i.e $N \gg 0.1$.

[53] The trace that the discharge leaves in the tidal gauges is an over-elevation of the water level. The water level observed, $\eta(x ; t)$ is locally separated into two components: (1) a low-frequency component $\eta_{Q}(x ; t)$ associated with the discharge and (2) another component, which is the oscillatory part associated with tidal dynamics, $\tilde{\eta}(x ; t)$. The total elevation $\eta$ is thus $\eta=\eta_{Q}+\tilde{\eta}$. The temporal evolution of $\tilde{\eta}$ in $a_{5}$, located in the central area of the estuary, has a good fit with the curve reconstructed on the basis of the harmonic analysis (Figure 12b). The fit improves during the spring tides when the tidal currents are stronger. During neap tides, the measured curves are ahead of the predicted curves by $1-1.3$ hours, depending on the magnitude of the discharge. This phase lag is uniform and there are no differences between phase lags of the high water and high-water slack and those of the low water and low-water slack.

[54] This result suggests that in the lower and middle stretches of the estuary, the water surface can be fairly approximated by the linear superposition of the tidal and river contributions [Godin, 1985; Horrevoets et al., 2004], at least while no overflowing of the banks and levees occurs. Figure $12 \mathrm{c}$ also shows data recorded by tidal gauge $\beta_{8}$ at 

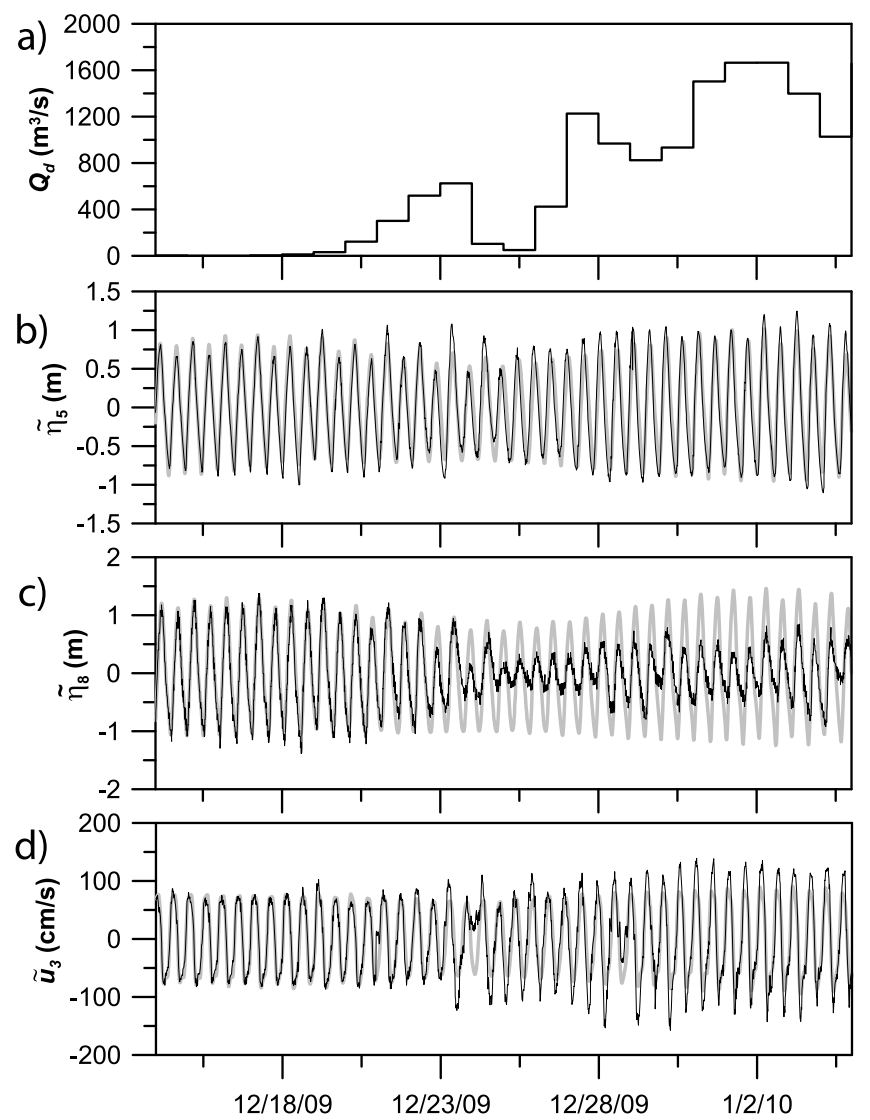

Figure 12. (a) The daily averaged discharge $Q_{d}$, (b) $\tilde{\eta}$ in tidal gauge $\beta_{5}$, (c) $\tilde{\eta}$ in tidal gauge $\beta_{8}$, and (d) the oscillatory part of the current in $\alpha_{3}$. In Figures $12 \mathrm{~b}-12 \mathrm{~d}$, the gray lines correspond with the tidal prediction and the black lines with the computed oscillatory part.

$10 \mathrm{~km}$ from the dam. At this station, the water level overflowed the levees in this zone. The tidal amplitude was damped $50-60 \%$ with respect to the tidal prediction, i.e., the normal, low-flow conditions.

[55] For the currents, the same method was used to separate the tidal and fluvial contributions. As shown in Figure 12d, no good fit was observed between the filtered and the predicted signals, not even in the current-meter closest to the estuary mouth. During the high river discharges period, the currents move towards negative values (downstream). This shift can be roughly estimated by $u_{F} \approx-Q_{d} / A$, where $A$ is the cross-section at the measurement point and $u_{F}$ is the associated river current. The oscillatory part of the velocity, i.e. the tidal contribution, almost doubles during the high flow. This amplification continues long after the discharge ceases exhibiting a relaxation period of 40-50 days.

\section{Conclusions}

[56] Tide propagation in the Guadalquivir estuary is analyzed and discussed. For most of the year, it is tidallydominated and $N \ll 0.1$. Under such conditions, the estuary, extending to the Alcalá del Río dam, $110 \mathrm{~km}$ upstream from the mouth, was divided into three stretches, each controlled by different tidal propagation processes. In the first stretch at the estuary entrance, approximately $25 \mathrm{~km}$ long, tidal propagation behaves like a diffusive process with a diffusion coefficient, $\kappa=1.9 \cdot 10^{5} \mathrm{~m}^{2} / \mathrm{s}$. In the following stretch, of $35 \mathrm{~km}$ length, shoaling, caused by channel convergence, and friction are in balance. Tidally-averaged values for the drag coefficient were obtained in the range $2.5 \cdot 10^{-3} \leq C_{D} \leq 5 \cdot 10^{-3}$. Upstream from this stretch up to the Alcalá del Río dam, the tidal motion is partially standing since the dominant process is reflection on the dam. The reflection coefficient of the tidal components was calculated, based on two water level data sets. The solution was obtained by assuming that incident and reflected wave transformations due to friction and the convergence of the channel are negligible in comparison to the reflection. The reflection coefficient $R$ varies with the frequency. Close to the dam, $R$ exhibits a maximum for quarter-diurnal components $\left(\left|R_{Q}\right| \approx 0.65\right)$ and a minimum for the sixth-diurnal $\left(\left|R_{X}\right| \approx 0.10\right)$. Intermediate values are obtained for the semidiurnal and diurnal constituents $\left(\left|R_{S}\right| \approx 0.40\right.$ and $\left|R_{D}\right| \approx 0.25$, respectively). Downstream, the reflection coefficient of the semidiurnal components decreases $\left(\left|R_{S}\right| \approx 0.25\right)$, and that of the quarter-diurnal components decreases even more significantly $\left(\left|R_{Q}\right| \approx 0.20\right)$.

[57] The tidal reflection can generate residual currents that have consequences in the bed morphology. Erosion-deposition patterns induced by the quasi-standing tidal dynamics were identified. The reflection of the $M_{4}$ constituent favors sedimentation in the area near the dam, and the reflection of the $M_{2}$ extends possible sedimentation to the areas near the entrance of the Port of Seville in the zone where the most intense dredging takes place.

[58] The estuary becomes fluvially-dominated when river discharges are larger than $400 \mathrm{~m}^{3} / \mathrm{s}$. The water surface can then be obtained by the linear superposition of the tide and river contributions as long as there is no overflowing of banks and levees. However, it was not possible to reconstruct the velocity signal at any of the measuring points by using this rule. Between the tidally-dominated and the fluvially-dominated regime, there is a wide range of intermediate fluvial-tidal regimes in which estuary dynamics moves seamlessly between the other two regimes.

\section{Appendix A: Separation of the Incident and Reflected Wave Train}

[59] To separate the incident wave from the reflected wave, based on the simultaneous signals recorded in three tidal gauges, the method used was the same as proposed by Baquerizo [1995]. The method assumes (1) that the wave train impinges normally on the reflecting element (this allows the problem to be studied in two dimensions); and (2) that the channel is uniform and frictionless (which means that the tidal amplitude, wavelength and phase are not modified by topography variations). Despite the considerable simplification, the location of the set of tidal gauges located at a distance of less than $15 \mathrm{~km}$ from the dam is closest to the ideal. As is shown in Figure 2, the Guadalquivir estuary is weakly convergent with a convergence length of $60.26 \mathrm{~km}$ (the estuary length is $110 \mathrm{~km}$ ) [ Jay, 1991]. This means that over the last $15 \mathrm{~km}(60.26 \mathrm{~km})$ the channel geometry can be regarded as approximately uniform. 
[60] There is a system of coordinates $(x, z)$ at the still water level with the $z$ axis pointing upwards and the $x$ axis positive in the opposite direction to the propagation of the incident wave train. Linear wave theory can be applied to obtain the free surface at the position of the nth tidal gauge, $x_{n}$, as follows:

$$
\eta_{n}=\left[Z_{i} e^{-i k x_{n}}+Z_{r} e^{i k x_{n}}\right] e^{-i \omega t},
$$

where $\omega$ is the angular frequency of the tide harmonic considered; $k$ is the wave number obtained as a solution of the dispersion equation, $\omega^{2}=g k \tanh (k h) ; Z_{i}$ and $Z_{r}$ are the complex amplitudes of the incident and reflected wave trains, respectively; $t$ is the time; and $i$ is the imaginary unit.

[61] $\varepsilon_{n}$ is defined as the absolute value of the difference between equation (A1) and the complex harmonic value measured in $x_{n}, C_{n}=A_{n} e^{i \phi_{n}}$, where $A_{n}$ is the complex amplitude and $\phi_{n}$ is the phase. $Z_{i}$ and $Z_{r}$ are obtained by looking for those values for which the minimum total mean square error is achieved:

$$
E\left(Z_{i}, Z_{r}\right)=\sum_{n=1}^{3} \epsilon_{n}^{2}=\sum_{n=1}^{3}\left|Z_{i} e^{-i k x_{n}}+Z_{r} e^{i k x_{n}}-C_{n}\right|^{2} .
$$

[62] Baquerizo [1995] showed that the minimum of this complex function is the solution of the system that is obtained after equating to zero the partial derivatives of $E$ with respect to $Z_{i}$ and $Z_{r}$ :

$$
\begin{aligned}
& Z_{i}=\frac{3 \cdot B_{2}-B_{1} \cdot S_{2}}{9-S_{2} \cdot S_{1}} \\
& Z_{r}=\frac{3 \cdot B_{1}-B_{2} \cdot S_{1}}{9-S_{2} \cdot S_{1}}
\end{aligned}
$$

where

$$
\begin{gathered}
B_{1}=\sum_{n=1}^{3} C_{n} \cdot e^{i k x_{n}} \\
B_{2}=\sum_{n=1}^{3} C_{n} \cdot e^{-i k x_{n}} \\
S_{1}=\sum_{n=1}^{3} e^{2 i k x_{n}} \\
S_{2}=\sum_{n=1}^{3} e^{-2 i k x_{n}} .
\end{gathered}
$$

\section{Appendix B: Mass Transport Calculation}

[63] The oscillatory movement in the region where the flow is essentially non-viscous and irrotational generates a net current $U_{L}$ in the bottom boundary layer. At order $\mathcal{O}\left(\omega k A^{2}\right)$, where $\omega$ is the angular frequency, $k$ is the wave number, and $A$ is a significant wave amplitude scale, such movement is composed of two terms: the Eulerian drift, $U_{e}$ and the Stokes drift, $U_{d}$ :

$$
U_{L}=U_{e}+U_{d}
$$

where

$$
\begin{aligned}
& U_{e}=-\frac{1}{\omega} \mathbb{R}\left\{F(\xi) U_{o} \frac{\partial U_{o}^{*}}{\partial x}\right\} \\
& U_{d}=\frac{1}{2 \omega} \mathbb{R}\left\{i G(\xi) U_{o} \frac{\partial U_{o}^{*}}{\partial x}\right\},
\end{aligned}
$$

[64] Here $\mathbb{R}$ designates the real part of the complex number, $U_{0}$ is the amplitude of the tidal component velocity with frequency $\omega,()^{\star}$ denotes the complex conjugate, and $\xi=z / h$. The functions $F(\xi)$ and $G(\xi)$ are given by

$$
\begin{aligned}
F= & \mathrm{e}^{\xi(i-1)}\left(\frac{3 i}{2}+\xi\left(\frac{i}{2}+\frac{1}{2}\right)-\frac{1}{2}\right)-\frac{3 i}{4} \\
& -\mathrm{e}^{-\xi(i+1)}\left(\frac{i}{2}+\mathrm{e}^{\xi(i-1)}\left(\frac{i}{4}+\frac{1}{4}\right)\right)+\frac{3}{4},
\end{aligned}
$$

$$
G=\mathrm{e}^{\xi(i-1)}(i-1)-\mathrm{e}^{-\xi(i+1)}-\frac{i-1}{\mathrm{e}^{2 \xi}}-\xi \mathrm{e}^{\xi(i-1)}(i-1)+1 .
$$

[65] See Mei [1989] for a detailed description. For a quasi-standing oscillation, whose incident and reflected amplitudes are, respectively, $Z_{i}$ and $Z_{r}$, the amplitude $U_{0}(x)$ is given by:

$$
U_{0}=\frac{c}{h}\left[Z_{i} e^{-i k x}-Z_{r} e^{i k x}\right]
$$

where $c=\sqrt{g h}$ is the wave celerity.

[66] Although the tidal flow is turbulent, and the boundary layer occupies the whole water column, the mass transport velocity is calculated at a location $z$, close to the bed, where the shear stresses are highest. The variable $z$ was chosen to match the width of the laminar boundary layer (estimated as $\delta=\sqrt{2 \nu / \omega}$, where $\nu$ is the kinematic viscosity), whose value is approximately $8-20 \mathrm{~cm}$ for the main tidal components.

\section{Appendix C: Calculation of the Drag Coefficient $C_{D}$}

[67] The equation that governs the along-estuary momentum results from the balance between the acceleration, the horizontal pressure gradient and the vertical turbulent stress gradient. Ignoring the convective terms, the following equation holds:

$$
\frac{\partial u}{\partial t}=-\frac{1}{\rho} \frac{\partial P}{\partial x}-\frac{1}{\rho} \frac{\partial \tau}{\partial z}
$$

where $u$ is the longitudinal velocity; $P$ is the pressure; $\rho$ is the water density; $h$ is the depth; and $\tau$ includes the internal and external tangential stresses on the fluid. If 
the longitudinal variation of the atmospheric pressure is assumed to be negligible, equation $(\mathrm{C} 1)$ becomes:

$$
\frac{\partial u}{\partial t}=-\frac{g(\eta-z)}{\rho} \frac{\partial \rho}{\partial x}-g \frac{\partial \eta}{\partial x}-\frac{1}{\rho} \frac{\partial \tau}{\partial z}
$$

[68] Integrating equation (C2) over the water depth $\int_{-h}^{\eta} d z$ and ignoring the tangential stress on the surface due to wind action, the following equation is obtained:

$$
\frac{\partial(\eta+h) \underline{u}}{\partial t}-u(\eta) \frac{\partial \eta}{\partial t}+\frac{g(\eta+h)^{2}}{2 \underline{\rho}} \frac{\partial \underline{\rho}}{\partial x}+g(\eta+h) \frac{\partial \eta}{\partial x}=\frac{1}{\underline{\rho}} \tau_{b},
$$

where the underlined magnitudes denote depth-averaged values, and $u(\eta)$ is the along-channel current evaluated at the free surface. The bottom friction can be expressed in terms of the depth-averaged horizontal velocity and a constant drag coefficient, $C_{D}$ as follows:

$$
\tau_{b}=\underline{\rho} C_{D} \underline{u}|\underline{u}| .
$$

[69] For the computation of the instantaneous value of $C_{D}$ at the central stretch, the values of $\eta, \underline{u}, \rho$ and their derivatives in equation (C3) were computed with data measured at tidal gauges $\beta_{3}$ and $\beta_{4}$, CTDs $\gamma_{4}$ and $\gamma_{5}$, and current meter $\alpha_{3}$, using finite differences in time and space.

[70] For the last term in left hand side of equation (C3), tidal elevations at $\beta_{3}$ and $\beta_{4}$ were used in the finite differences scheme to estimate the spatial derivative. Salinity, temperature and pressure measurements at CTDs combined into the state equation [United Nations Educational, Scientific and Cultural Organization, 1981], allowed to compute the vertical averaged density $\rho$ at the corresponding kilometer points. Depth averaged velocities $\underline{u}$ were estimated with data from the current-meter, $\alpha_{3}$, representative of the stretch that extends from $\beta_{3}$ to $\beta_{4}$.

[71] Solving the resulting equation, the time series of $C_{D}$ was finally computed for non zero values of $\underline{u}$.

[72] Acknowledgments. This research was funded by the Spanish Ministry of Science and Innovation (project CTM2009-10520/MAR) and by the Department of Innovation, Science and Business of the Andalusian Regional Government through the project P09-TEP-4630 and a research contract between the University of Granada and the CSIC (under the direction of the Port Authority of Seville). The authors would like to thank the two anonymous reviewers for their valuable comments and suggestions, which have greatly improved this paper.

\section{References}

Álvarez, O., B. Tejedor, and J. Vidal (2001), La dinámica de marea en el estuario del Guadalquivir: un caso peculiar de 'resonancia antrópica' (in Spanish), Fis. Tierra, 13, 11-24.

Ambar, I., and M. Howe (1979), Observations of the mediterranean outflow-II The deep circulation in the vicinity of the Gulf of Cádiz, Deep Sea Res., Part A, 26(5), 555-568.

Ávila, A. (2007), Procesos de múltiple escala en la evolución de la línea de costa (in Spanish), PhD thesis, Univ. of Granada, Granada, Spain.

Baquerizo, A. (1995), Reflexión del oleaje en playas: Métodos de evaluación y de predicción (in Spanish), PhD thesis, Univ. of Cantabria, Cantabria, Spain.

Baquerizo, A., M. A. Losada, J. Smith, and N. Kobayashi (1997), Crossshore variation of wave reflection from beaches, J. Waterw. Port Coastal Ocean Eng., 123, 274.
Baquerizo, A., M. A. Losada, and J. Smith (1998), Wave reflection from beaches: A predictive model, J. Coastal Res., 14(1), 291-298.

Blanton, J. O., G. Lin, and S. A. Elston (2002), Tidal current asymmetry in shallow estuaries and tidal creeks, Cont. Shelf Res., 22, 1731-1743.

Bramato, B., E. Contreras, M. J. Polo, A. Baquerizo, G. Navarro, M. DíezMinguito, and M. A. Losada (2009), Dynamics of suspended sediments in the Guadalquivir estuary: Monitoring network and database management, in Environmental Hydraulics-Theoretical, Experimental and Computational Solutions, Taylor and Francis, Philadelphia, Pa.

Cheng, P., A. Valle-Levinson, and H. de Swart (2011), A numerical study of residual circulation induced by asymmetric tidal mixing in tidally dominated estuaries, J. Geophys. Res., 116, C01017, doi:10.1029/ 2010JC006137.

Contreras, E., and M. J. Polo (2010), Propuesta metodológica para diagnosticar y pronosticar las consecuencias de las actuaciones humanas en el estuario del Guadalquivir (in Spanish), technical report, Group of Fluvial Dyn. and Hydrol., Univ. of Córdoba, Córdoba, Spain.

Costa, S., J. M. Gutiérrez-Mas, and J. A. Morales (2009), Establecimiento del régimen de flujo en el estuario del Guadalquivir mediante el análisis de formas de fondo con sonda multihaz (in Spanish), Rev. Soc. Geol. España, 22(1-2), 23-45.

Dronkers, J. (2005), Dynamics of Coastal Systems, Adv. Ser. on Ocean Eng., vol. 25, World Sci., Hackensack, N. J.

Dyer, K. R. (1997), Estuaries: A Physical Introduction, 2nd ed., John Wiley, Chichester, U. K.

Friedrichs, C., and D. Aubrey (1994), Tidal propagation in strongly convergent channels, J. Geophys. Res., 99, 3321-3336.

Friedrichs, C. T., and D. G. Aubrey (1988), Nonlinear tidal distortion in shallow well-mixed estuaries: A synthesis, Estuarine Coastal Shelf Sci., 27, 521-545.

Friedrichs, C. T., and O. S. Madsen (1992), Nonlinear diffusion of the tidal signal in frictionally dominated embayments, J. Geophys. Res., 97, 5637-5650.

Friedrichs, C. T., B. D. Armbrust, and H. E. De Swart (1998), Hydrodynamics and equilibrium sediment dynamics of shallow, funnel shaped tidal estuaries, in Physics of Estuaries and Coastal Seas, pp. 315-328, Balkema, Rotterdam, Netherlands.

García-Lafuente, J., and J. Ruiz (2007), The Gulf of Cádiz pelagic ecosystem: A review, Prog. Oceanogr., 74, 228-251.

García-Lafuente, J., J. Delgado, F. Criado-Aldeanueva, M. Bruno, J. del Río, and J. M. Vargas (2006), Water mass circulation on the continental shelf of the Gulf of Cádiz, Deep Sea Res., Part II, 53, 1182-1197.

Geyer, W., J. Trowbridge, and M. Bowen (2000), The dynamics of a partially mixed estuary, J. Phys. Oceanogr., 30(8), 2035-2048.

Geyer, W. R., and R. Chant (2006), The Physical Oceanography Processes in the Hudson River Estuary, pp. 24-38, Cambridge Univ. Press, New York.

Godin, G. (1985), Modification of river tides by the discharge, J. Waterw. Port Coastal Ocean Eng., 111, 257.

González-Ortegón, E., M. D. Subida, J. A. Cuesta, A. M. Arias, C. FernándezDelgado, and P. Drake (2010), The impact of extreme turbidity events on the nursery function of a temperate european estuary with regulated freshwater inflow, Estuarine Coastal Shelf Sci., 87, 311-324.

Grimalt, J. O., M. Ferrer, and E. Macpherson (1999), The mine tailing accident in Aznalcóllar, Sci. Total Environ., 242, 3-11.

Hansen, D. V., and M. Rattray (1966), New dimensions in estuary classification, Limnol. Oceanogr., XI(3), 319-326.

Hickey, B., et al. (2010), River influences on shelf ecosystems: Introduction and synthesis, J. Geophys. Res., 115, C00B17, doi:10.1029/2009JC005452.

Horrevoets, A., H. Savenije, J. Schuurman, and S. Graas (2004), The influence of river discharge on tidal damping in alluvial estuaries, J. Hydrol., 294(4), 213-228.

Jay, D., B. Giese, and C. Sherwood (1990), Energetics and sedimentary processes in the Columbia River estuary, Prog. Oceanogr., 25(1-4), 157-174.

Jay, D. A. (1991), Green's law revisited: Tidal long-wave propagation in channels with strong topography, J. Geophys. Res., 96(C11), 20,585.

Lanzoni, S., and G. Seminara (1998), On tide propagation in convergent estuaries, J. Geophys. Res., 103(C13), 30,793.

Longuet-Higgins, M. (1953), Mass transport in water waves, Philos. Trans. R. Soc. London, Ser. A, 245(903), 535.

Losada, I., M. A. Losada, and A. Baquerizo (1993), An analytical method to evaluate the efficiency of porous screens as wave dampers, Appl. Ocean Res., 15(4), 207-215.

Mei, C. (1989), The Applied Dynamics of Ocean Surface Waves, vol. 1 World Sci., Hackensack, N. J.

Navarro, G., F. J. Gutierrez, M. Díez-Minguito, M. A. Losada, and J. Ruiz (2011), Temporal and spatial variability in the Guadalquivir estuary: A challenge for real-time telemetry, Ocean Dyn., 61(6), 753-765. 
Navarro, G., I. E. Huertas, E. Costas, S. Flecha, M. Díez-Minguito, I. Caballero, V. López-Rodas, L. Prieto, and J. Ruiz (2012), Use of a Real-Time Remote Monitoring Network (RTRM) to characterize the Guadalquivir estuary (Spain), Sensors, 12(2), 1398-1421.

Pawlowicz, R., B. Beardsley, and S. Lentz (2002), Classical tidal harmonic analysis including error estimates in MATLAB using T-TIDE, Comput. Geosci. 28, 929-937.

Prandle, D. (2003), Relationships between tidal dynamics and bathymetry in strongly convergent channels, J. Phys. Oceanogr., 33(12), 2738-2750.

Prandle, D. (2004), How tides and river flows determine estuarine bathymetries, Prog. Oceanogr., 61(1), 1-26.

Prandle, D., and M. Rahman (1980), Tidal response in estuaries, J. Phys. Oceanogr., 10, 1552-1573.

Prieto, L., G. Navarro, S. Rodríguez-Gálvez, I. Huertas, J. Naranjo, and J. Ruiz (2009), Oceanographic and meteorological forcing of the pelagic ecosystem on the Gulf of Cádiz Shelf (SW Iberian Peninsula), Cont. Shelf Res., 29(17), 2122-2137.

Savenije, H. H. G., and E. J. M. Veling (2005), Relation between tida damping and wave celerity in estuaries, J. Geophys. Res., 110, C04007, doi:10.1029/2004JC002278.

Scully, M., and C. Friedrichs (2007), The importance of tidal and lateral asymmetries in stratification to residual circulation in partially mixed estuaries, J. Phys. Oceanogr., 37(6), 1496-1511.

Sherwood, C., D. Jay, R. Bradford Harvey, P. Hamilton, and C. Simenstad (1990), Historical changes in the Columbia River estuary, Prog. Oceanogr., 25(1-4), 299-352.
Speer, P. E., and D. G. Aubrey (1985), A study of non-linear tidal propagation in shallow inlet/estuarine systems. Part II: Theory, Estuarine Coastal Shelf Sci., 21, 207-224.

Tatavarti, R., D. Huntley, and A. Bowen (1988), Incoming and outgoing wave interactions on beaches, in Coastal Engineering, pp. 136-150, Am. Soc. of Civ. Eng., Reston, Va.

Uncles, R. (2002), Estuarine physical processes research: Some recent studies and progress, Estuarine Coastal Shelf Sci., 55(6), 829-856.

United Nations Educational, Scientific and Cultural Organization (1981), Tenth report of the joint panel on oceanographic tables and standards, UNESCO Tech. Pap. Mar. Sci., 36, 24 pp.

Vanney, J. R. (1970), L'hydrologie du bas Guadalquivir (in French), Inst. Geogr. Aplic. "Alonso de Herrera," Cons. Super. Invest. Cient., Madrid. Wright, L., and A. Short (1983), Morphodynamics of beaches and surf zones in Australia, in CRC Handbook of Coastal Processes and Erosion, pp. 35-64, CRC Press, Boca Raton, Fla.

A. Baquerizo, M. Díez-Minguito, M. A. Losada, and M. Ortega-Sánchez, Grupo de Dinámica Flujos Ambientales, Centro Andaluz de Medio Ambiente, IISTA, Universidad de Granada, Avda. del Mediterráneo, s/n, E-18006 Granada, Spain. (abaqueri@ugr.es; mdiezm@ugr.es; mlosada@ugr. es; miguelos@ugr.es)

G. Navarro, Department of Ecology and Coastal Management, Instituto de Ciencias Marinas de Andalucía, Consejo Superior de Investigaciones Científicas, E-11510 Puerto Real, Spain. (gabriel.navarro@icman.csic.es) 